\title{
Energy Innovation and the Sustainability Transition
}

Matthew Hannon

Hunter Centre for Entrepreneurship

University of Strathclyde

matthew.hannon@strath.ac.uk

Ronan Bolton

Science, Technology and Innovation Studies

University of Edinburgh

ronan.bolton@ed.ac.uk

Hannon, M., Bolton, R., (2021) Energy Innovation and the Sustainability Transition, in Rubino, A., Sapio, A., La Scala, M. (eds.) Handbook of Energy Economics and Policy:

Fundamentals and Applications for Engineers and Energy Planners (1st Edition). Academic Press, 2021 


\section{Introduction}

We live during a period when our energy system is undergoing intense and radical change. Underpinning this transformation are a wide range of drivers, including energy security and affordability. Chief amongst these however is climate change, which has spurred international action to overhaul the largely fossil-fuel based energy system. This is enshrined in the landmark Paris Climate Agreement signed in 2015 by 195 countries at the $21^{\text {st }}$ Conference of the Parties (COP21), obligating all parties to limit global temperature rise to less than $2^{\circ} \mathrm{C}$ above pre-industrial levels (UNFCCC, 2016).

World leaders at Paris emphasised the critical role energy technology innovation will play in achieving this goal, culminating in the international Mission Innovation initiative. This is an agreement between 23 countries and the European Commission (on behalf of the European Union) to double their clean energy research, development and demonstration (RD\&D) investment by 2020/2021 (Mission Innovation, 2019). As these parties represent more than $80 \%$ of today's global clean energy RD\&D budgets, this signifies a major global push to accelerate energy innovation and deliver a transition to a sustainable energy system. Whether such high-level political commitments will have a significant material effect on our energy systems remains to be seen however.

The development and subsequent deployment of new energy technologies lies at the heart of energy system change, however a sustainable energy system transition demands much more than technological innovation. Transformational change across a myriad of social and technical dimensions, including policy, markets, culture, science and user preferences, are all required. It is these inter-connected domains that shape the way in which we satisfy consumers' energy needs, such as warmth, light and mobility. Energy system change is highly complex and unpredictable given how these different dimensions co-evolve, simultaneously shaping and being shaped by one another. This can result in positive feedbacks between these system dimensions that 'lock-in' the existing fossil fuel based energy system and in turn 'lock-out' more environmentally-friendly alternatives.

In this context this chapter employs a system-level perspective on energy innovation and transitions (see definitions in Box 9.1 below), where transformative change depends on a coordinated and long-term approach that treats the energy system as an interconnected, nested 'whole'. To achieve this end there is a need for a suite of conceptual tools that offer insights into how and why energy system change is unfolding. 


\section{Box 9.1 - Summary of definitions for energy innovation and transitions}

Energy innovation - the process of putting new ideas into practice through an iterative process of research, development, demonstration and deployment - yielding alternative and potentially improved means of satisfying our need for energy services.

Sustainable energy transition - a fundamental transformation across all energy system domains (e.g. technologies, institutions, markets, user practices etc.) that culminates in an energy system capable of satisfying our energy needs in an environmentally and socially responsible fashion for both current and future generations.

\section{$1.1 \quad$ Learning objectives}

The chapter is aimed at all those interested in strategies to accelerate sustainable energy innovation and support a low-carbon transition, relevant to those from a research, policy, industry or NGO background. For those keen to model the future energy transition the chapter offers insight into the dynamics of innovation and system change, which will help modellers calibrate the parameters and underpinning assumptions used in their models. The chapter's learning objectives include exploring: (1) definitions of energy innovation and transitions; (2) ongoing trends in energy innovation, (3) analytical frameworks to help us understand both how and why energy innovation and wider system change unfold. To help illustrate these topics we make reference to 'real-world' examples.

\subsection{Chapter structure}

The chapter begins in the next section with an overview and discussion of scenarios and visions of a sustainable energy system. Energy system scenarios illustrate that the scope and magnitude of system change involved in transitions is quite different to our traditional understanding of technology-based innovation involving new devices, products etc. Our energy systems are complex configurations of energy sources, infrastructures, markets, regulatory frameworks, and services based around human activities. 'Whole system' change as new configurations is a form of innovation requiring an appreciation of the interconnectedness of these social and material elements of energy systems at different societal levels, from individual behaviours, to the structure of industries, to broader societal and normative visions of the role of energy in our lives. We pay particular attention to the 
Sustainable Development Scenario (SDS) which is based around achieving the Paris Agreement and the UN's Sustainable Development goals.

Energy system innovation poses challenges for innovation studies, both in terms of how innovation is measured and appraised, and how it is conceptualised. Section 2 considers the breadth and depth of energy 'whole system' change associated with a sustainability transition. Section 3 provides an overview of key innovation trends and discuss whether the current pace of innovation is commensurate with the ambition implied in transformative scenarios such as SDS. Following this, in Section 4 we provide an overview of three separate but related fields of innovation studies - evolutionary economics, innovation systems and socio-technical transitions - and how these offer different insights into energy innovation and transitions. Section 5 presents the chapter's conclusions.

\section{Energy transitions as 'whole system' change}

\subsection{What is a sustainable energy system transition?}

In the broadest sense an energy transition represents a transformation of the energy system over a prolonged period of time. So what constitutes a sustainable energy transition? The answer to this question is highly contested and evolving, as too is the timeframe in which such a system must be realised, to avoid crises relating to climate change, energy security etc. There is however a growing sense of agreement that a sustainable energy system is one that delivers high levels of energy security and affordability but not at the expense of environmental health and social equity.

We can liken a system transition to a journey in the sense that there are many different paths that can be taken to reach the same destination. Related to this point is the extent to which a transition to a sustainable energy system relies on radical and disruptive innovation versus less disruptive, incremental innovation. Some definitions of a sustainable energy transitions emphasise the role of radical transformation. For example, Foxon defines 'a transition to low carbon systems of energy supply and energy service provision will require radical changes to technologies, institutions, business strategies and user practices; hence, it raises governance challenges in relation both to the engagement of different actors and to the incentives and barriers they face' (Foxon, 2013 p.11). In contrast carbon emissions could be realised by incumbent firms driving incremental innovations of established technologies. For example, since 2004 the fuel economy of cars and trucks has increased by $5.4 \mathrm{mpg}$, or $28 \%$, with an average annual improvement of about $0.5 \mathrm{mpg}$ per year (USEPA, 2018). Major 
improvements in gas turbine efficiency have also been achieved, seeing improvements from 18\% thermal efficiency in 1939 (Robb, 2010), with 62\% having been achieved in 2016 by General Electric, a major incumbent multi-national energy firm (GE, 2016).

There are however legitimate concerns about the where the limitations of these incremental performance improvements lie and whether such a strategy is compatible with avoiding catastrophic climate change. In the words of Mulder (2007) 'improved technology may be the enemy of truly sustainable technology' (p.262). In reality, a sustainable energy system is likely to rely on both the emergence of radically new energy technologies and business models, alongside incremental improvements to existing ones.

\subsubsection{The IEA's World Energy Outlook Sustainable Development Scenario}

To offer a sense of perspective on the scale of transformation required to realise sustainable energy systems we present the International Energy Agency's (IEA) Sustainable

Development Scenario (SDS) from its World Energy Outlook 2018 and contrast this with two other far less ambitious scenarios: the Current Policies Scenario (CPS), and the New Policies Scenario (NPS). All three scenarios see world population from $7.5 \mathrm{bn}$ in 2017 to $9.2 \mathrm{bn}$ by 2040 and GDP more than double from \$127tn \$276tn over the same period. However, the similarities end here and the core differences between the three scenarios are outlined below:

- Current Policies Scenario (CPS) - 'considers the impact of those policies and measures that are firmly enshrined in legislation as of mid-2018. It provides a cautious assessment of where momentum from existing policies might lead the energy sector in the absence of any other impetus from government' (IEA, 2019e). This scenario broadly correlates with business as usual, leading to 'increasing strains on almost all aspects of energy security and a major additional rise in energy-related $\mathrm{CO}_{2}$ emissions' (IEA, 2019f).

- New Policies Scenario (NPS) - 'provides a sense of where today's policy ambitions seem likely to take the energy sector. It incorporates not just the policies and measures that governments around the world have already put in place, but also the likely effects of announced policies, including the Nationally Determined Contributions made for the Paris Agreement' (IEA, 2019e).. 
- Sustainable Development Scenario (SDS) - an integrated approach that delivers on the emissions reductions outlined by the Paris Agreement ${ }^{1}$ and the United Nations Sustainable Development Goals (SDGs) ${ }^{2}$ including universal energy access (SDG 7), reducing impacts of air pollution (part of SDG 3) and tackling climate change (SDG 13) (IEA, 2019f, 2019e). It is also sensitive to SDG 6 on access to clean water.

Looking back carbon emissions more than doubled between 1973 and 2018 from $15.4 \mathrm{Gt}$ $\mathrm{CO}_{2}$ to $33.1 \mathrm{Gt} \mathrm{CO}_{2}$ (IEA, 2019b), a historical high. Whilst emissions growth slowed significantly during the mid-2010s it has once again signalled strong growth due to higher energy demand in 2018 (IEA, 2019b). Looking forward SDS is the only one of the three scenarios to reverse the long-term historical trend of growing carbon emissions, achieving a $46 \%$ drop by 2040 versus 2017, whilst emissions under CPS actually rise $30 \%$ and are up 10\% under NPS (Figure 9.1).

Figure 9.1: Carbon emissions from fuel combustion (Source: IEA, 2018d)

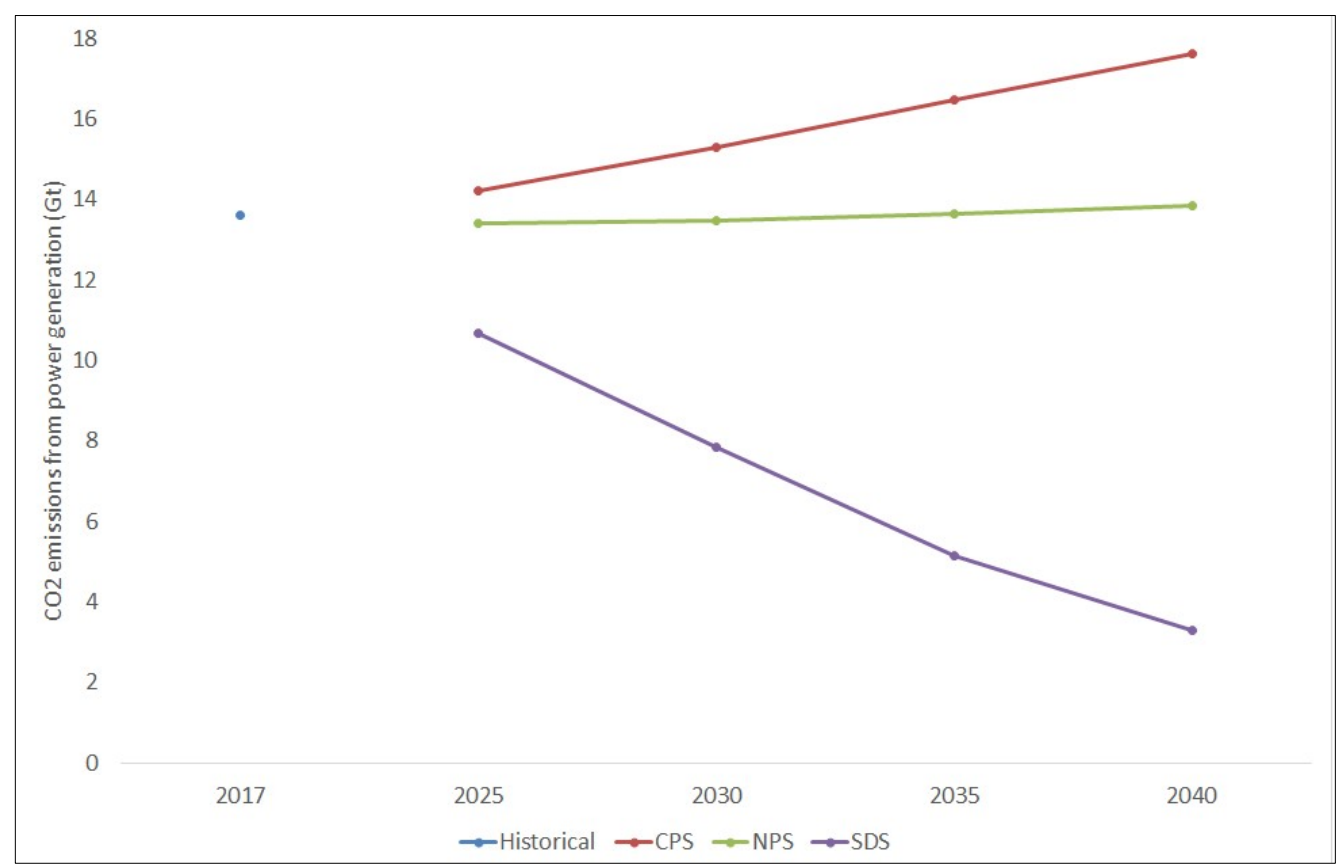

\footnotetext{
${ }^{1}$ It is important to note that IEA's SDS is in line with constraining temperature rise to below $2{ }^{\circ} \mathrm{C}$ above preindustrial levels, however the Intergovernmental Panel on Climate Change (IPCC) recently published a report warning that $2{ }^{\circ} \mathrm{C}$ warming above pre-industrial levels risked potentially catastrophic consequences (IPCC, 2018). This has led to growing calls to limit warming to $1.5^{\circ} \mathrm{C}$, however the IEA's SDS is consistent with 1.7$1.8^{\circ} \mathrm{C}$ warming.

${ }^{2}$ Compared to the other two scenarios SDS sees 'sharp reductions in emissions of air pollutants lead to significantly cleaner air, bringing considerable health benefits: premature deaths from outdoor air pollution are half a million lower in 2040 than today' (p.82). It also achieves universal access to electricity, clean cooking and clean water. However, at its heart is mitigation of climate change.
} 
Changes in energy demand are central to this envisaged fall in emissions under SDS.

Historically total primary energy supply more than doubled between 1973 and 2016, from 71 PWh to 160 PWh (IEA, 2018b). This would have been much higher but energy efficiency gains since 2000 prevented 12\% more energy use in 2017 (IEA, 2018c p.13). Looking forward SDS is the only scenario where total primary energy demand ${ }^{3}$ remains at 2017 levels despite a dramatic rise in population, economic wealth and access to electricity. In contrast the other two scenarios see $27 \%$ (NPS) and 38\% (CPS) rise.

To achieve this SDS takes advantage of 'all economically viable avenues to improve efficiency are pursued, keeping overall demand in 2040 at today's level' (IEA, 2019f). This efficiency drive sees the energy intensity under SDS fall by more than half from $1.28 \mathrm{kWh} / \$$ GDP in 2017 to 0.58 in 2040, versus 0.75 under NPS kWh/\$ GDP and $0.81 \mathrm{kWh} / \$$ GDP under CPS. Under the last two scenarios the fall in energy intensity is are offset by a dramatic growth in energy demand, primarily from developing countries, especially in Asia.

Whilst energy demand plays a key role, decarbonisation of global energy supply is the other major contributor to emissions reduction, especially in the power sector. Carbon intensity of our power supply fell from $532 \mathrm{gCO}_{2} / \mathrm{kWh}$ in 1990 to $490 \mathrm{gCO}_{2} / \mathrm{kWh}$ in 2016 , an $8 \%$ fall over 26 years. However, under SDS this falls by an impressive 86\% between 2017 and 2040; a period 3 years shorter. Even under the other scenarios we witness a substantial reduction, falling 35\% under NPS and $21 \%$ under CPS.

Unsurprisingly this fall in carbon intensity is largely achieved by a major shift away from fossil fuels. As illustrated in Figure 9.2, Coal's dominance comes to an end under the SDS, with its share of generation falling from $38 \%$ to $5 \%$. Gas also sees a dramatic fall from $23 \%$ to $14 \%$ and oil falls from $4 \%$ to just $1 \%$. Together fossil fuels' share falls from $65 \%$ to $20 \%$ by 2040 . Filling this gap is a dramatic increase in renewables, whose share grows from $24 \%$ to $66 \%$, with the most notable contributors being wind (21\%), hydro (19\%) and solar PV (17\%). Together the total generation from renewables quadruples during the period to 2040, whilst fossil fuel power outputs falls by more than half. The rise of intermittent technologies

\footnotetext{
${ }^{3}$ Total primary energy demand (TPED) represents domestic demand only and is broken down into power generation, other energy sector and total final consumption. According to the IEA this is equivalent to TPES (IEA, 2019c)
} 
such as solar PV and wind power gives unprecedented importance to the flexible operation of power systems in order to 'keep the lights on'.

Figure 9.2: Power generation and carbon intensity of electricity in the SDS (Source: IEA, 2018d)

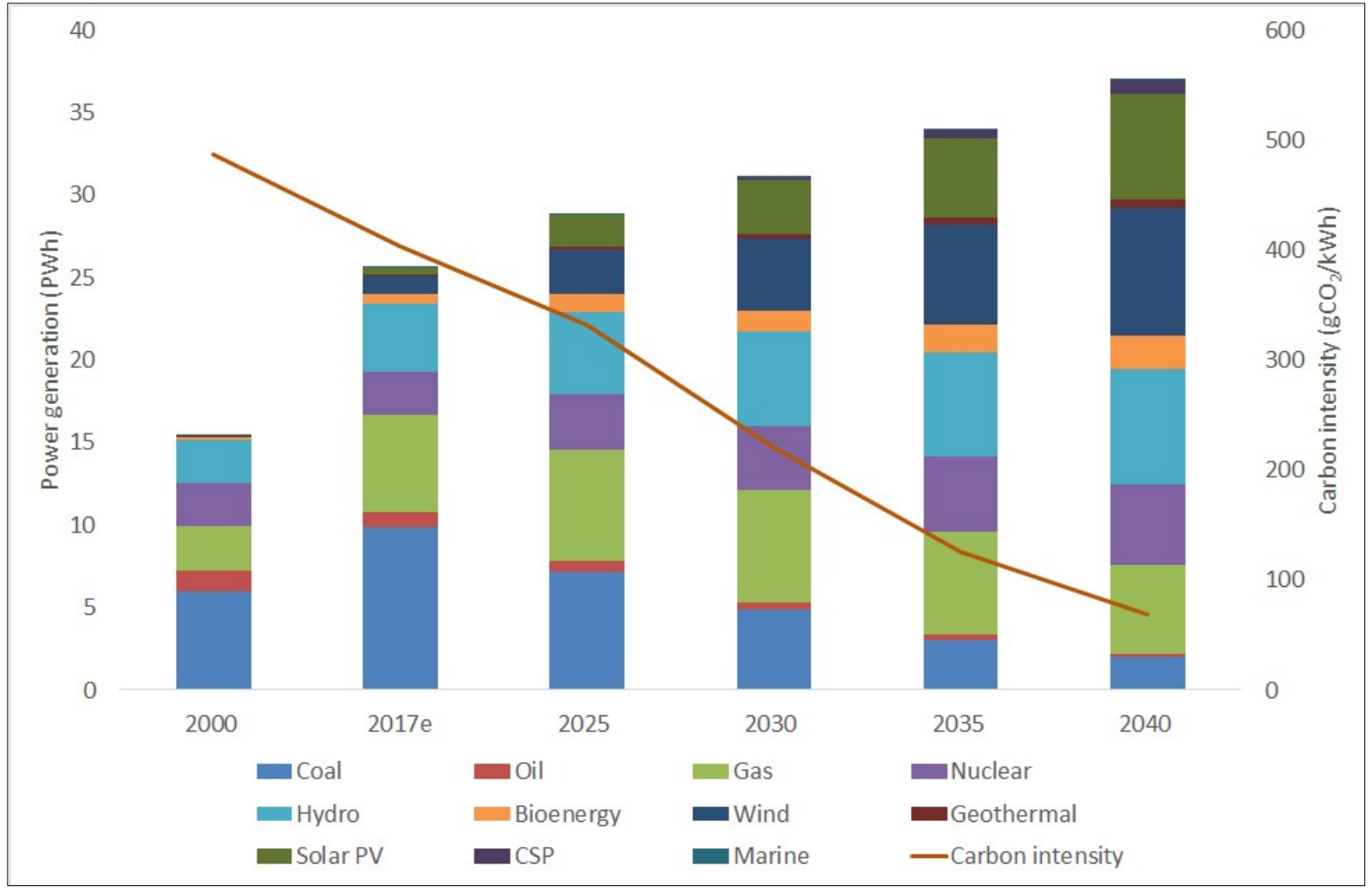

Looking beyond the energy and power supply sectors we find that the transition under the SDS will involve a fundamental change in the way consumers and businesses consume energy across transport, buildings and industry. In general we see major efficiency gains alongside a dramatic shift towards end-use consumption of electricity (

Figure 9.3). For example, electricity consumption grows by half between 2017 and 2040, and electricity's share of final consumption grows up from $19 \%$ to $28 \%$. 
- Transport: Vehicle stock of trucks grows by $40 \%$ and cars by $60 \%$ but emissions fall by $15 \%$ and $50 \%$ respectively. This is achieved via two ways:

1. Improvements in efficiency of internal combustion engines (ICEs), with ICE cars $40 \%$ more efficient than today, saving over 9 million barrels of oil per day by 2040 .

2. Shifting fuel use away from oil, namely electricity or low-carbon fuels. For example, growing from just 3 million EVs worldwide, numbers reach more than 900 million by 2040 , accounting for over $50 \%$ of the fleet, whilst $25 \%$ of buses become electric. Today oil makes up $92 \%$ of transport energy consumption but under SDS this falls to $60 \%$ by 2040 , whilst electricity's share grows from $1 \%$ to $14 \%$. We also find a significant growth in biofuels and other fuels like hydrogen. For example, nearly $20 \%$ of fuels used by trucks are low or zero carbon by 2040 .

- Buildings: Despite an additional 1.7 billion people, energy demand from buildings actually falls. Again this can in part be attributed to significant efficiency gains, with the energy intensity of residential buildings falling by almost $40 \%$, indicating a fundamental change in the design and fabric of our building stock. The share of electricity also grows from $32 \%$ to $49 \%$. Whilst this is largely attributed to growth in electricity demand from increased use of air conditioning and appliances in the developing world, there is also shift away from both fossil fuels and biomass towards electrical heating like heat pumps or direct renewables like solar thermal, geothermal and modern biomass. Whilst oil's share falls from $11 \%$ to $7 \%$, and coal use becomes negligible, we find gas retains a $24 \%$ share of energy consumption in buildings, versus $22 \%$ in 2017 .

- Industry: 'The only end-use sector to see a substantial increase in energy consumption from 2017 to 2040: energy efficiency gains in industry do not quite keep up with growth of industrial economic output' (IEA, 2018d p.90), with a $20 \%$ in energy demand. Consequently, the $17 \%$ reduction in carbon emissions is achieved largely through adoption of industrial motors, which account for a third of the world's appetite for increased electricity. There is also shift away from direct use of coal and oil towards gas, electricity and the direct use of solar thermal and geothermal. 
Figure 9.3: Comparison of 2017 total final consumption (Source: IEA, 2018d) 

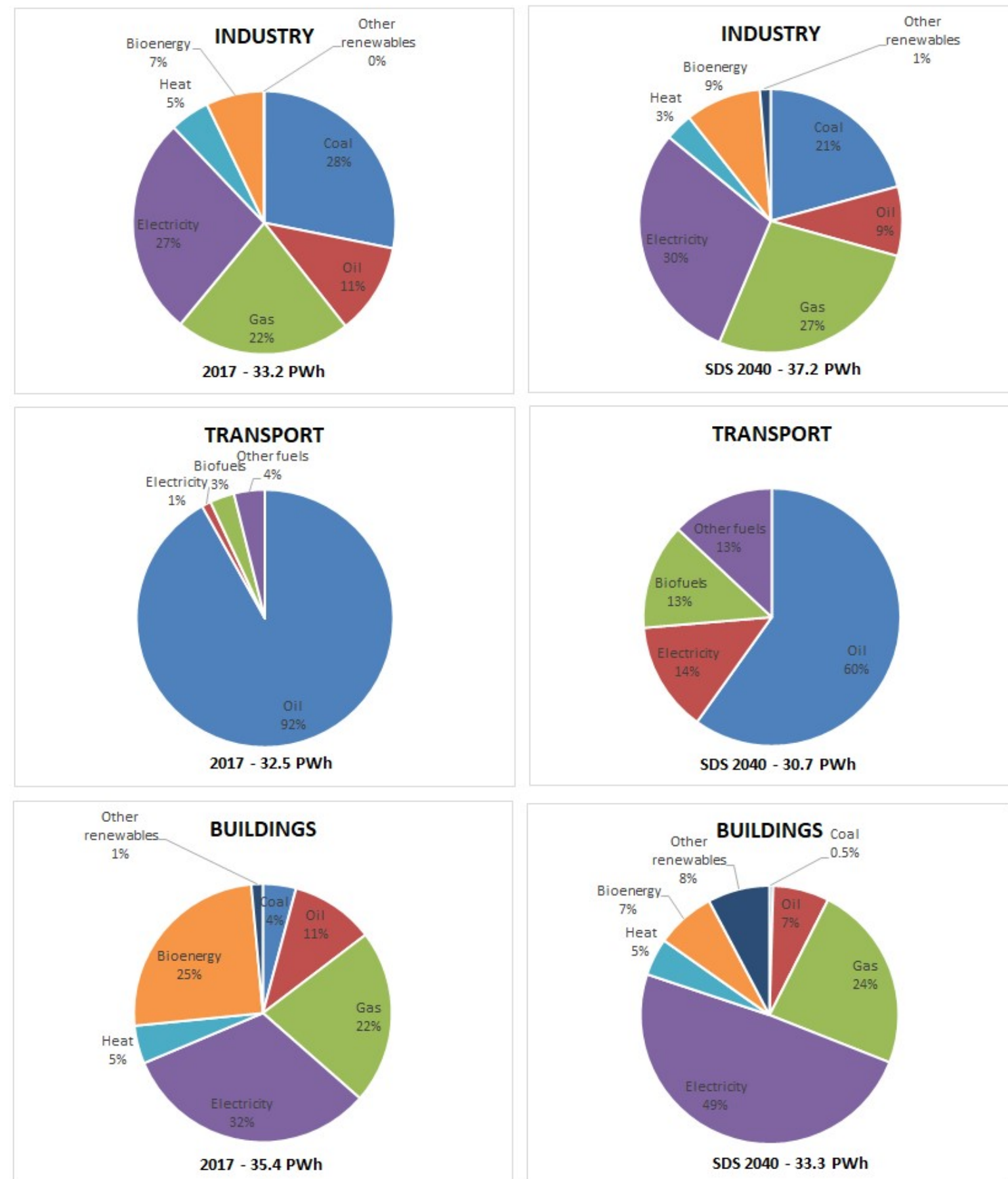

TRANSPORT
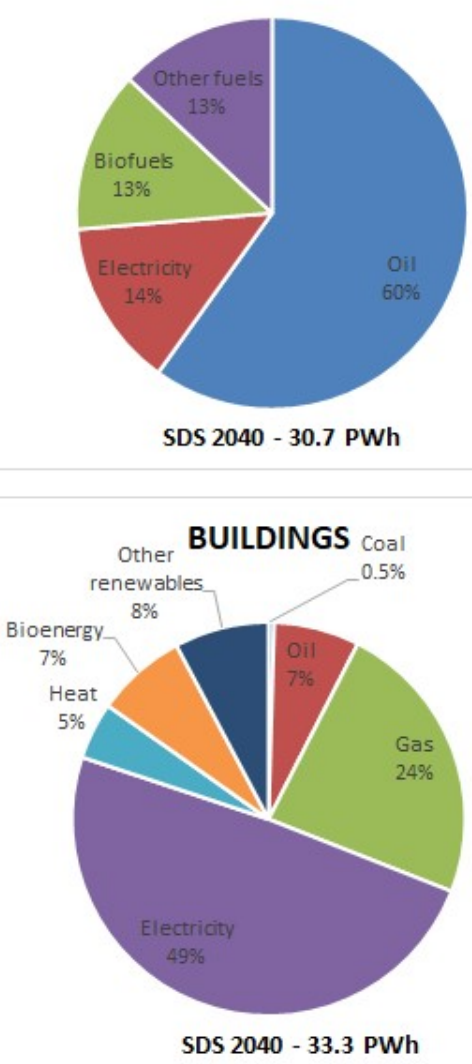

To realise the SDS vision the average annual investment needs to increase versus the status quo CPS scenario by $16 \%$, up to $\$ 3.3$ trn/pa between 2026 and 2040 . Underlying this is a significant shift from investment in fossil fuels supply and power generation to low-carbon fuel supply, power generation, infrastructure and end-use efficiency. Here we see the share of fossil fuel investment falls from 50\% in CPS to 19\% of total investment, with absolute investment more than halving. In contrast the share of low-carbon investment grows from $50 \%$ to $81 \%$ per annum, whilst absolute investment almost doubling to $\$ 2.6 \mathrm{bn}$. 
Whilst much of this investment is for technology deployment, underpinning this transformative innovation is significant RD\&D investment to stimulate technology innovation. It is clear just how integral new energy technologies are to the IEA's SD Scenario. For instance, two-thirds of remaining coal generation is from plants equipped with CCUS, amounting to $210 \mathrm{GW}$ of coal plant capacity by 2040 . Today there are only 18 CCUS plants currently operational worldwide (Global CCS Institute, 2019). We also find that generation from marine power grows more than 70 fold and concentrating solar power almost 80 fold. In parallel there are also significant improvements in existing technologies like a $40 \%$ efficiency gain in internal combustion engines.

\section{Trends in sustainable energy innovation}

The IEA's SDS points to the tectonic shifts that are required across our energy system over the coming decades in order to meet our sustainable development objectives. Underpinning this scenario, both explicitly and implicitly, is wide-scale technological innovation across the whole energy system. In the following sub-section we examine the recent pace of low-carbon technology innovation to assess what progress is being made to realise this vision. Adopting Hu et al.'s (2017) synthesized framework we examine energy research, development and demonstration (RD\&D) investment as a low-carbon energy innovation inputs - the resources that feed into the innovation process - before turning to patents, levelised cost and the energy supply mix as three innovation outputs - the intermediary impacts generated by these inputs. We focus our attention on the power sector as this is integral to the SDS, where many of the end-use sector undergo extensive electrification. For all the positive indications highlighted, it is clear however that significant work remains to deliver a sustainable energy system.

\subsubsection{Inputs}

\subsubsection{Energy RD\&D investment}

Public investment in energy $R D \& D^{4}$ grew rapidly in parallel with the onset of the oil crisis and a political drive in many countries to diversify energy sources and reduce reliance on what were perceived as untrustworthy oil-rich countries. Investment in energy RD\&D

\footnotetext{
${ }^{4}$ RD\&D investment covers 'the design, construction, and operation of a prototype of a technology at or near commercial scale' (IEA, 2011 p.15). The data excludes deployment, which covers 'the selection and use of a commercially available technology-based product or service in normal operations by businesses, individuals or government agencies with the aim of accelerating the diffusion and adoption of technologies or practices' (ibid p.15). It refers to public budgets rather than actual spend across 30 countries plus the European Commission. This also includes state-owned companies.
} 
initially peaked in 1979 and then declined rapidly during the 1980s, again in conjunction with falling oil prices. It started to recover from the late 1990s before reaching a peak of $\$ 22.5 \mathrm{bn}$ in 2009 (Figure 9.4). Investment has declined a little since then, with a total budget of $\$ 19 \mathrm{bn}$ in $2016^{5}$.

If we compare the three years 1976, 1996 and 2016 - each 20 years apart - we find that the mix of technologies being invested in has changed dramatically (Figure 9.5). Firstly, the share given over to nuclear has declined dramatically, falling from $66 \%$ in 1976 to just $20 \%$ in 2016. Secondly, whilst the share given over to fossil fuels has fluctuated, its long-term average is a $13 \%$ share since 1974 , typically remaining between $10-20 \%$. However, the past few years we have seen this share decline from $15 \%$ in 2013 to $9 \%$ in 2016 . This fall corresponded with a decline in annual average crude oil import prices from $\$ 106 /$ barrel in 2013 to $\$ 41 /$ barrel in 2016, however this has since risen to $\$ 68$ in 2018 (IEA, 2019d), which may signal a revival in oil RD\&D to drive down costs. A similar trend can be witnessed for gas prices in most countries post-2013 (IEA, 2019a).

Thirdly, we note that replacing the drop in nuclear RD\&D investment have been a widerange of low-carbon technologies including renewables, energy efficiency, storage and hydrogen. For instance, renewables' share in 2016 was 20\%, versus its long-term average since 1974 of $12 \%$. If we compare 2016 to 1996 we also see how the budget for energy efficiency grew from $13 \%$ to $18 \%$, whilst that for other power and storage rose from $4 \%$ to $9 \%$ and hydrogen and fuel cells grew to a 3\% share from almost nothing.

\footnotetext{
${ }^{5}$ The fall between 2015 and 2016 can to some extent be accounted for by a lack of data for either Ireland or Portugal, however this would not for the full $\$ 310 \mathrm{~m}$ drop in funding.
} 
Figure 9.4: Public clean energy RD\&D investment between 1974 and 2016 (Source: IEA, 2018a)

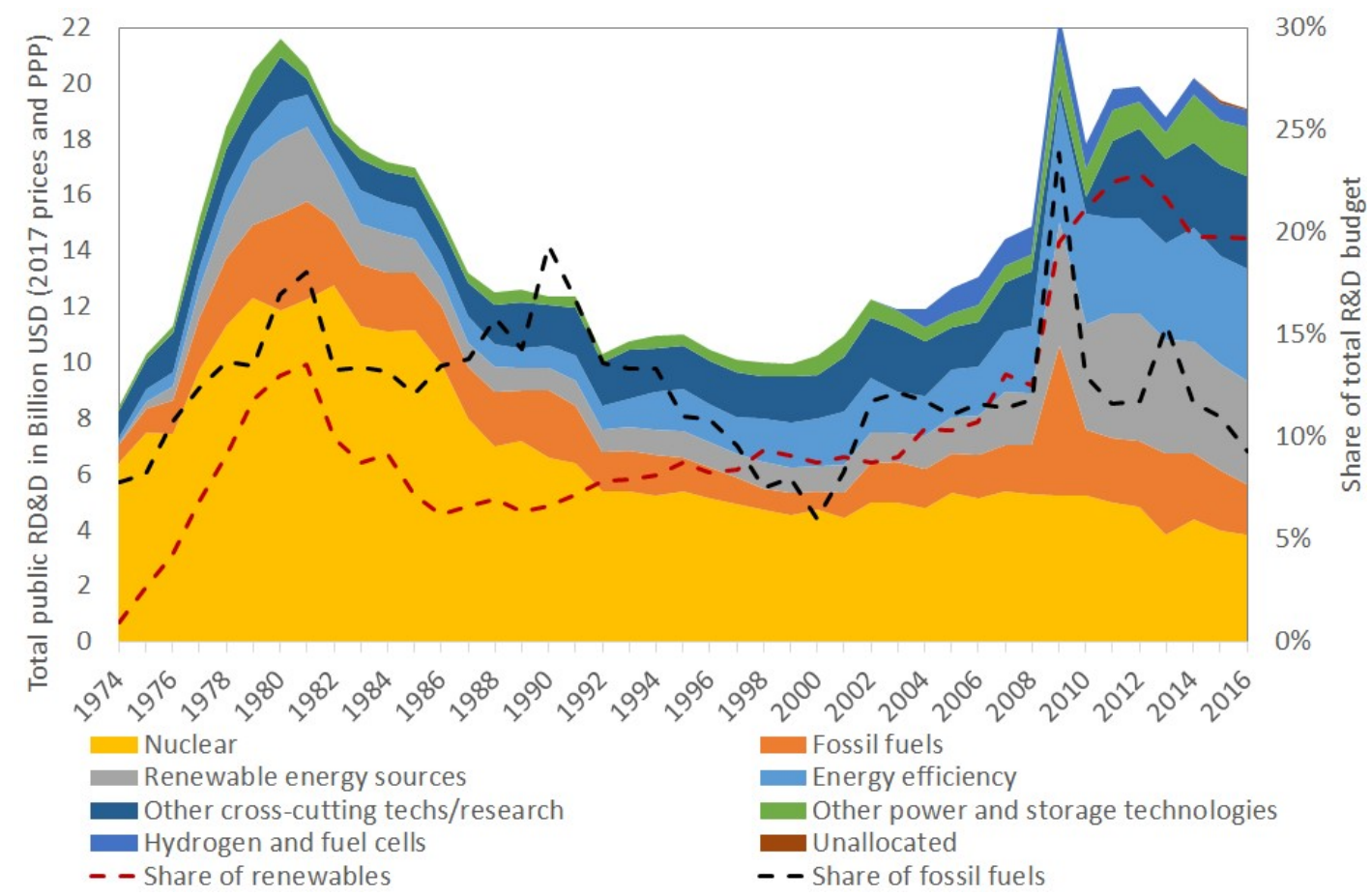

Figure 9.5: Comparison of public energy RD\&D investment between 1976, 1996 and 2016 (Source: IEA, 2018a)

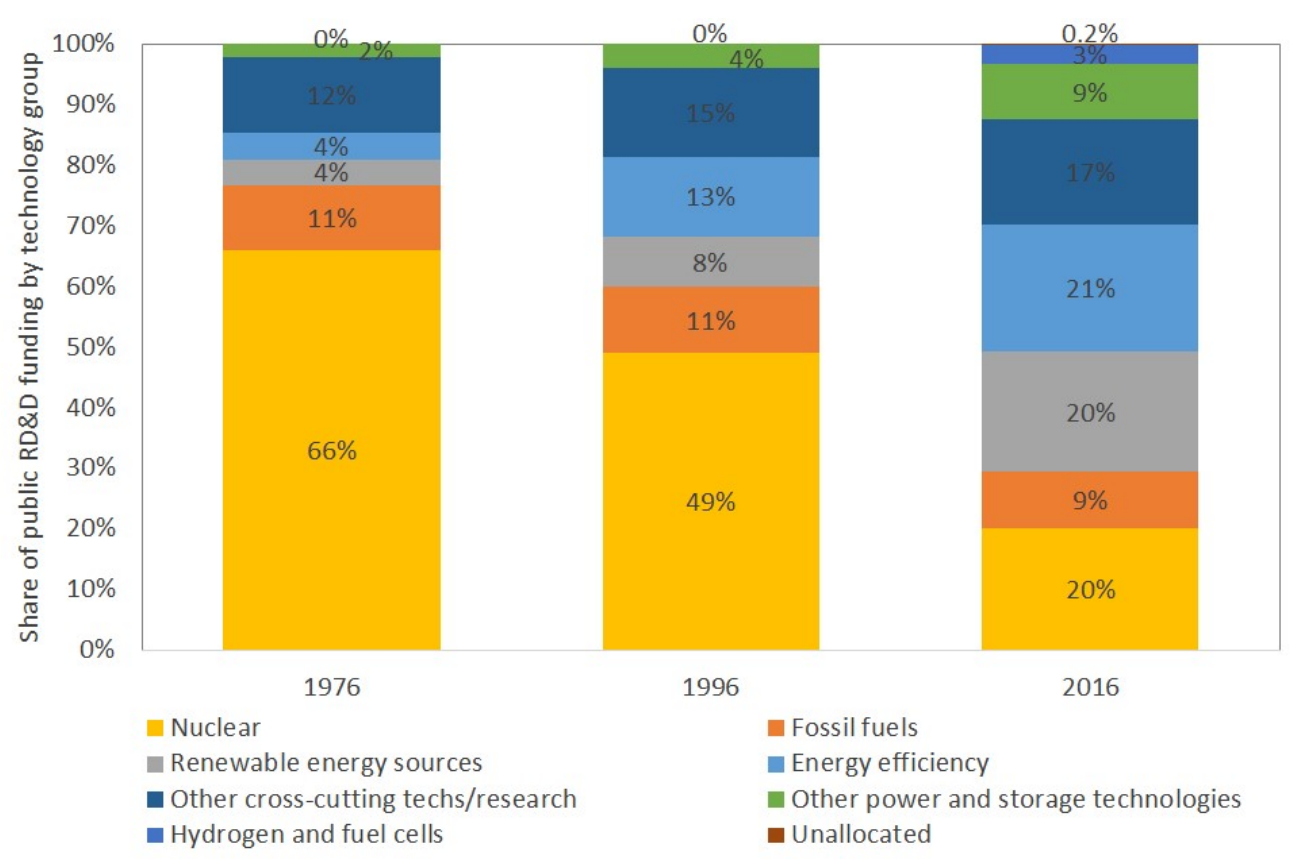




\subsubsection{Outputs}

\subsubsection{Energy technology patents}

Covering 79 countries IRENA charts the evolution of low-carbon energy patents since 2000.

Patents are a useful (but not a perfect) indicator of the degree of early to mid-stage innovation activity, where the fundamentals of the technology are proven prior to larger scale prototyping. Looking across the period between 2000 and 2016 we find a dramatic increase in the absolute number of renewable energy patents up to 2011 but then a similarly dramatic fall (Figure 9.6). Net additions of patents grew by more than five times between 2000 and 2011 but by 2015 this fell to half that of 2011 and back down to 2007 levels. Whilst this could be an indicator of lower levels of innovation, there could be a broad range of explanations ranging from renewable technology moving beyond early-to-mid stage of innovation where patenting is most common, to a change in culture around the value of patenting. Interestingly, the mix of patents across technologies changed little between 2000 and 2015.

Figure 9.6: Renewable energy patent filings 2000 to 2015 (Source: IRENA, 2019)

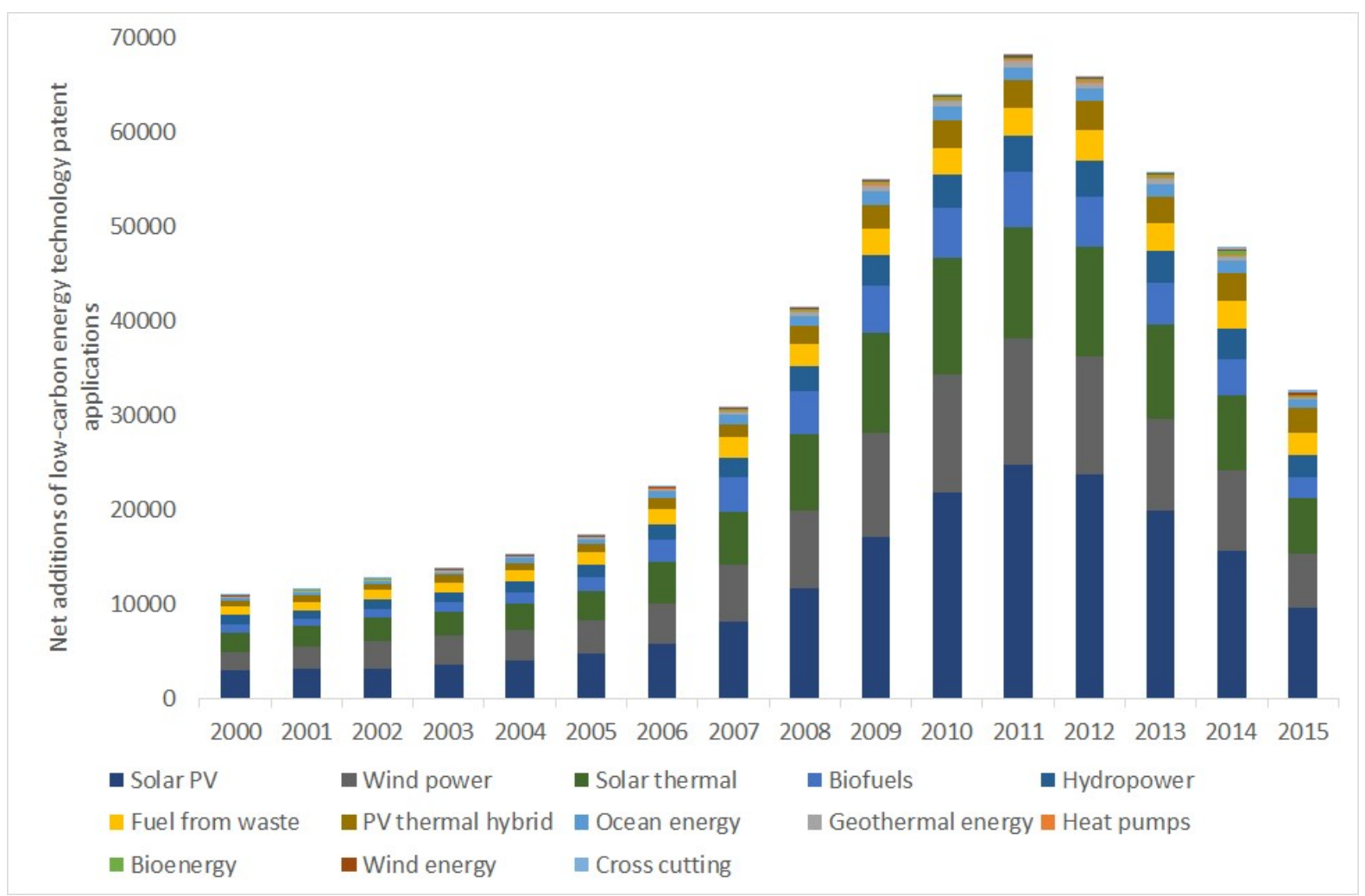

NOTE: Data for 2016 was available but omitted as unclear whether it covered just part or the whole year. 
In contrast to renewable energy technologies, fossil fuel patents have seen growth in recent years, with the number of oil and gas patents 34\% higher in 2015 versus 2006, with the majority of new patents stemming from earth drilling to support new means of oil and gas extraction (Deloitte, 2017). However, it should be noted that growth has slowed since 2013.

\subsubsection{Levelised cost of power generation technologies}

The levelised cost of electricity (LCOE) ${ }^{6}$ is another important indicator of the progress of energy technology innovation.

Figure 9.7 provides a cross-comparison of different renewable energy LCOEs for 2017 versus 2010, including a comparison against fossil fuel costs. We find that four of the six renewable technologies have become cheaper during this seven years period, the exceptions being geothermal and hydro. Solar PV witnessed a dramatic reduction, with the average price falling from $0.36 \$ / \mathrm{kWh}$ to $0.1 \$ / \mathrm{kWh}$.

Five of the six renewable technologies (excluding concentrating solar power) were comparable with the LCOE range for fossil fuel power (i.e. between $0.05 \$ / \mathrm{kWh}$ and $0.17 \$ / \mathrm{kWh}$ ), whilst hydro was on average cheaper than fossil fuels. This suggests that some renewable energy technologies are now able to compete with fossil fuels purely on a cost basis, without the need for subsidies.

Looking forward this trend is set to continue for some renewables, with the global weighted average levelised cost of electricity (LCOE) of solar PV potentially falling by as much as $59 \%$, concentrating solar power (CSP) by up to $43 \%$, and onshore and offshore wind seeing declines of $26 \%$ and 35\%, respectively (Taylor, Ralon and Ilas, 2016).

\footnotetext{
${ }^{6}$ IRENA define LCOE for a given technology as 'the ratio of lifetime costs to lifetime electricity generation, both of which are discounted back to a common year using a discount rate that reflects the average cost of capital.' They use 'a fixed assumption of a real cost of capital of 7.5\% in OECD countries and China, and 10\% in the rest of the world, unless explicitly mentioned'. Finally, 'all LCOE calculations exclude the impact of any financial support' (IRENA, 2018b p.16).
} 
Figure 9.7: Comparison of levelised cost of energy technologies 2010 and 2017 (Source: IRENA, 2018b)

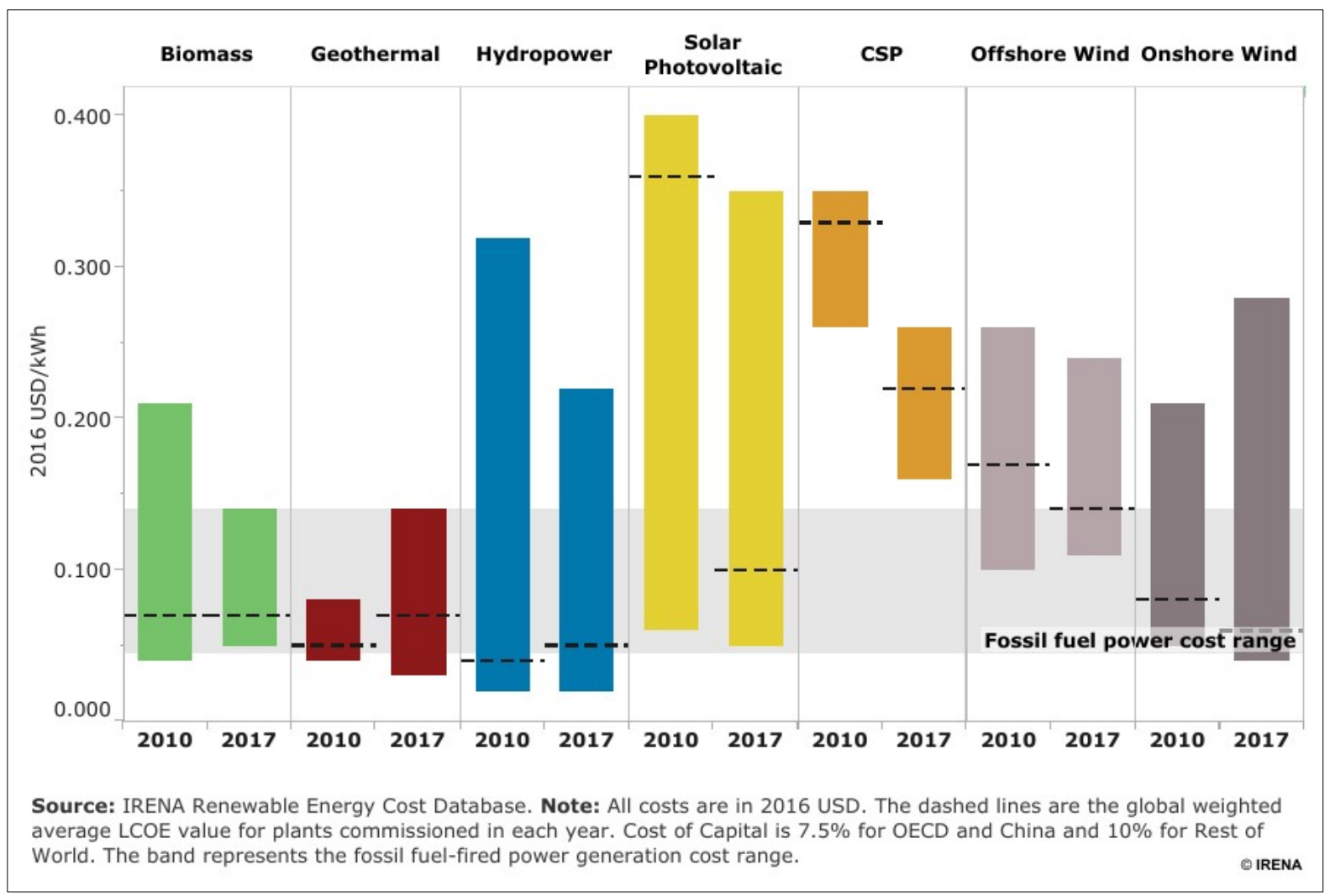

NOTE: The thick lines are the global weighted average LCOE value for plants commissioned in each year.

\subsubsection{Low-carbon power supply}

The growth of low-carbon generation has been much more pronounced in the power sector. Here low-carbon generation grew from $25 \%$ to $35 \%$ between 1973 and 2016 . This is largely accounted for by a growth in non-hydro renewables and nuclear, offsetting the fall in hydro generation. This growth has translated into a dramatic decline of oil (25\% to $4 \%)$, whilst coal retains its share of $38 \%$ and gas almost doubled its share from $12 \%$ to $23 \%$ (IEA, 2018b).

So which renewable technologies were responsible for the doubling of renewable generation since 2000? Drawing upon IRENA's global database on renewable electricity generation we find that hydro added 1.4 PWh to the grid, whilst onshore wind 0.9 PWh, solar PV 0.32 PWh and biofuels 0.26 PWh in 2016 versus 2000 (IRENA, 2018a). Over the past five years the strongest growing sectors have been solar PV $(+511 \%)$, offshore wind $(+400 \%)$ and concentrating solar power $(+361 \%)$. 


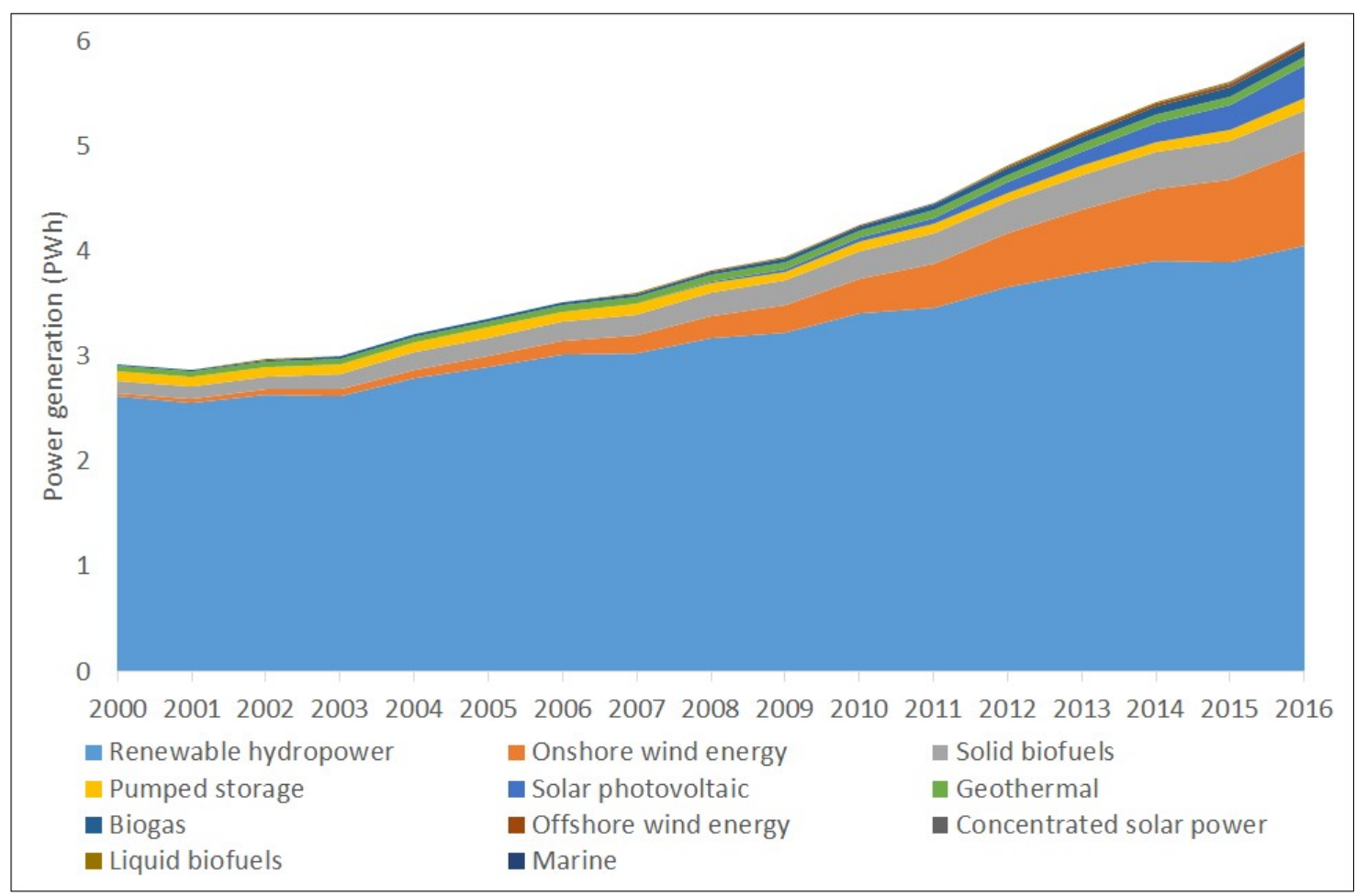

This impressive growth in renewable generation is a result of a major roll-out of renewable energy technologies from the 2000s onwards, growing from 0.84 TW in 2000 to 2.3 TW in 2017 (IRENA, 2018a). We find that in the early 2000s roughly 20GW of new renewable energy capacity was being added to the grid per annum, versus $170 \mathrm{GW}$ in 2017 . The latter is equivalent to adding 53 of the UK's new Hinkley Point $C^{7}$ nuclear power plants each year.

\section{Delivering a sustainable energy system: the need for insights from innovation and transitions studies}

For the remainder of this chapter we concentrate on operationalising innovation studies theories and concepts for the purposes of understanding sustainable energy transitions. Before discussing particular insights from the innovation studies literature, we outline below the basic rationale for an innovation studies approach and some foundational insights which have underpinned thinking in the field.

There are three main reasons why an innovation approach to energy and sustainability challenges is useful and necessary. Firstly, innovation studies literature can help us better

\footnotetext{
${ }^{7}$ EDF's new Hinkley Point C power plant will incorporate two $1.6 \mathrm{GW}$ reactors, giving a nameplate capacity of $3.2 \mathrm{GW}$.
} 
understand what conditions are required to accelerate the pace of innovation and ensure that investment in innovation is delivered effectively (see Section 5.2). Whilst Section 3 points to how excellent progress has been made thus far in terms of low-carbon innovation, we have to dramatically increase the pace of innovation over the next 20 years. This requires knowledge of which structural elements must be put in place to foster technological innovation and provide these new technologies a route to market. An important starting point is to capture lessons about how we have succeeded in driving forward low-carbon innovation in some areas (e.g. wind, solar PV) but struggled thus far in others that are considered critical to delivering a sustainable energy system (e.g. marine, CCUS).

Secondly, the IEA's SDS points to some of the fundamental changes we are likely to experience across power, buildings, transport and industry sectors. Innovation studies highlights how such transformation cannot simply be achieved by technological innovation alone but must unfurl alongside symbiotic business model, finance and government policy innovation too. This is because on the one hand these complementary forms of innovation are critical to the adoption of new technologies and on the other that change can be achieved simply by using old technologies in a new way (see Section 5.1).

Thirdly, the literature takes into account both the social and technical dimensions of an energy system to consider why they are so difficult to transform. For example, it is sensitive to not just the 'stickiness' of large-scale infrastructure but also how difficult it is to transform entrenched social norms; both of which need to change to deliver on sustainable development goals. Furthermore, it takes into account how these dimensions co-evolve, for example infrastructure shapes our consumption practices but these practices also shape our infrastructure needs (see Section 5.1). It is this complex inter-connectedness of social and technical components that makes an energy transition so challenging. However, by highlighting these challenges the innovation studies literature helps identify opportunities to deliver transformative energy system change through breaking this 'system lock-in', such as re-aligning the status quo through the formation of niche markets (see Section 0).

Finally, innovation studies can also help refine energy scenarios like the IEA's SDS, for two main reasons. The first is that the systems modelling that underpins these scenarios often incorporates imperfect representations of economic agent behaviour (Spataru, 2017), for example treating investors and/or consumers as fully rational economic decision makers when they rarely act as such (Section Error! Reference source not found.). The second is that they also include unrealistic or relatively simplistic assumptions (Spataru, 2017), for 
instance around technological innovation and rates of learning and efficiency improvements. The authors acknowledge the vital role of scenario development plays in helping to inform decision making, however such scenarios can over-simplify the nature of energy system change, given its highly unpredictable and complex nature. Innovation and transitions studies can help such scenarios more accurately reflect the true dynamics of energy innovation and system change (e.g. bounded rationality, technological lock-in).

\subsection{Defining energy innovation and system change}

\subsubsection{Innovation, invention and diffusion}

Joseph Schumpeter first began to theorise about the characteristics and dynamics of innovation in the early $20^{\text {th }}$ century conceptualising innovation as a process that involved at least one of the following five outcomes (Schumpeter, 1934):

- introduction of a new good;

- introduction of a new method of production;

- opening of a new market;

- conquest of a new source of supply of raw materials or half-manufactured goods;

- implementation of a new form of organization.

Schumpeter (1942) argued that innovation represents a form of 'creative destruction', where something new is forged from the destruction of something old. He viewed innovation as the lifeblood of capitalism:

'Capitalism, then, is by nature a form or method of economic change and not only never is but never can be stationary...[It] incessantly revolutionizes the economic structure from within, incessantly destroying the old one, incessantly creating a new one. This process of Creative Destruction is the essential fact about capitalism.' (Schumpeter, 1942 p.82-3)

Schumpeter also made the distinction between invention and innovation. Invention constitutes the generation and application of new ideas (e.g. new products, new methods of production), whilst innovation represents the taking advantage of inventions to generate economic benefit. He identified the entrepreneur, either an individual or collective, as the agent of innovation:

'The function of entrepreneurs is to reform or revolutionize the pattern of production by exploiting an invention or, more generally, an untried technological possibility for 
producing a new commodity or producing an old one in a new way' (Schumpeter, 1942 p.132)

Diffusion is also distinguished from either invention or innovation. Closely associated with adoption it represents the "process by which an innovation is communicated through certain channels over time among the members of a social system... the planned and the spontaneous spread of new ideas.' (Rogers, 1962 p.5-7). Importantly, we see different segments of society adopting innovations at different stages; Rogers broke these down as follows: (1) innovators; (2) early adopters; (3) early majority; (4) late majority; and (5) laggards (Rogers, 1962).

Modern definitions of innovation are heavily inspired by Schumpeter's work. For the purposes of this chapter we adopt the definition used by Grübler et al. (2012), where innovation constitutes 'putting ideas into practice through an (iterative) process of design, testing, and improvement' (p. 1673). Helpfully they differentiate this from invention 'the origination of an idea as a solution to a perceived problem or need' and diffusion 'the widespread uptake of an innovation throughout the market of potential adopters' (p. 1673).

\subsection{A typology of innovation}

Taking Freeman \& Perez's (1988) typology of innovation we can disaggregate innovation into four different categories, each referring to different degrees of change: incremental, radical, technology system and techno-economic paradigm:

Incremental innovation is 'in line with the prevailing technological paradigm and often improve the performance of existing technologies' (van den Bergh et al., 2006 p.59). It typically reinforces the status quo rather than disrupting it because whilst 'their combined effect is extremely important in the growth of productivity, no single incremental innovation has dramatic effects' (Freeman and Perez, 1988 p.46). In the energy sector incremental innovation often takes the form scaling up of generation facilities (e.g. wind turbines rated capacity) and improvements in efficiency (e.g. vehicle's miles per gallon).

Radical innovation is at odds with the prevailing technological paradigm and represents a step-change in technological development rather than a continuation. For example, nuclear power could not have emerged from incremental innovation of fossil fuel power generation technologies (Freeman and Perez, 1988). They are therefore typically the result of a targeted effort to deliver a novel technology via extensive RD\&D. They typically combine product, process and organisational innovations (Freeman and Perez, 1988) and can emerge from the 
synthesis of two or more stand-alone technologies, for example the windmill, which 'combined the ideas of the water mill and the sail' (Mokyr, 1992 p.44-45).

Technology system innovation represents combinations of radical and incremental innovations, both technological and non-technological (e.g. new business models). These can have a dramatic effect on the economy, potentially transforming existing sectors or creating entirely new ones. For example, the music industry has been transformed by new technology systems that combine of hardware (e.g. smart phone, internet), software (e.g. streaming apps, mobile operating systems) and business model (e.g. freemium business model) innovations. In the energy system we may take the example of domestic solar PV systems being combined with novel 'rent-a-roof ${ }^{8}$ business models that rely on policy innovations in the form Feed-inTariffs, which have enabled a proliferation in domestic solar PV generation in countries like the UK.

Techno-economic paradigm innovation constitutes major changes to the prevailing logic that dictates the behaviour and structure of entire economic system. Related to this last category is the concept of Kondratieff waves or K-waves, which was further developed by Schumpeter as part of his work on business cycles. Both point to how innovations are concentrated during particular periods of time and closely aligned with periods of intense economic growth as these. Flanking each phase of rapid economic growth are periods of stagnation in the form of economic depressions. Each wave is associated with specific technology systems, such as the railways in the mid to late $19^{\text {th }}$ century or automobiles in the mid to late $20^{\text {th }}$ century, each having a profound impact on the techno-economic paradigm shaping the wider economy (Korotayev, Zinkina and Bogevolnov, 2011).

Energy related technologies and processes have played a key role in many of these waves, including steam engines, railways, electrification and automobiles. Taking the example of electricity, it fundamentally changed the way our economy operates, underpinning a widerange of transformative socio-economic trends such as automation, communications and computing.

\footnotetext{
${ }^{8}$ The rent-a-roof model involves companies installing solar panels on homes free-of-charge, providing the customer with free electricity. The quid pro quo is that they receive, in full, the feed-in-tariff subsidy.
} 


\section{Energy innovation and wider system change}

Theorising and analysing change at the level of energy systems is challenging as it requires a joint understanding of the political and economic factors which influence interactions between both social (people, organisations and institutions) and technical (existing infrastructure and new innovations) components of systems. Our aim is not to cover the entire landscape in relation to innovation and socio-technical transition studies, but rather to offer an overview of how three inter-related approaches offer complementary insights into how and why energy innovation and systems transitions unfold: evolutionary economics (Section 5.1), innovation systems (Section 5.2) and socio-technical transitions (Section 0). We illustrate how these approaches have been operationalised by researchers to study innovation in the energy sector.

\subsection{Why are energy systems difficult to change? Insights from evolutionary theory}

This sub-section considers what insights can be gained from evolutionary theory to help explain how and why energy innovation and transitions take place. It focuses on the broad discipline of evolutionary economics, which 'offers insights into the mechanisms that underlie innovations, structural changes and transitions, therefore making it of great value in framing policies aimed at stimulating environmental innovations and transitions to sustainable development' (van den Bergh et al., 2006 p.57). Many of the insights in innovation systems (Section 5.2) transitions theory (Section 0) about the dynamics of sociotechnical change (e.g. positive feedbacks) are grounded in this theoretical perspective, representing an important starting point. Its key strengths lie in helping us to understand that innovation and transitions constitute long-run, complex processes, shaped by history and characterised by the fitness of innovations with their wider environment.

\subsubsection{Evolutionary understanding of technological change}

The pioneering ideas of Schumpeter (Section 4.1.1) provide the foundation to evolutionary economics. Offering a critique of neoclassical economics, this stresses that economies and markets are not in static equilibrium but are instead in continuous turmoil, subject to a 'perennial gale of creative destruction'. Underpinning the very heart of this theory is the view that evolutionary mechanisms, that have been developed to explain change in the natural world, can in fact help explain change how and why change unfolds in social, economic and technological systems too (Hodgson, 2005). The fundamental mechanisms driving evolution are those of variation, selection and retention, which are outlined in Box 9.1. 


\section{Box 9.1 - Evolutionary mechanisms in non-biological contexts}

- Variation represents novelties such as technological inventions or cultural memes (e.g. routines, songs)(Dawkins, 1976), which are analogous to genetic mutations. Unlike in biological systems, non-biological variation may be the outcome of conscious design, with a specific purpose in mind (Mayr, 1991; Cordes, 2006), and these variations may be developed with some insight into their degree of fitness the wider selection environment (Cordes, 2006).

- Selection refers to the multitude of forces that selectively eliminate variations (Aldrich and Ruef, 2006), together making up the selection environment. The degree of fitness a variation shares with its selection environment determines whether it is adopted and diffused by other agents or not. Unlike in biological contexts, human agents typically have some ex ante discretion over whether they select particular variations or not (Cordes, 2006), shaped by their perception of how well past variations have fared (Campbell, 1960; Heylighen, 1992).

- 'Retention occurs when variations are preserved, duplicated, or otherwise reproduced so that the selected activities are repeated on future occasions or the selected structures appear again in future generations' (Aldrich and Ruef, 2006) (p.23). In this sense, habits, routines and institutions do not just persist but are replicated via learning and replication (Hodgson, 2002). Replication is however often imperfect, leading to new variations that are related but characteristically different (Hodgson, 2002; Aldrich and Ruef, 2006).

Continuing this trend, the pioneering work of Nelson \& Winter (1982) sought to explain how evolutionary theory could be applied to the case economic and technological change.

Analogous to genes in the natural world they conceptualised the role of 'routines', , subject to the same evolutionary processes. These shape a firm's behaviour, determining its fitness with its wider environment and thus its likelihood of succeeding.

In time of stress firms may search for better techniques, which will in turn reshape their routines. (Foxon, 2003; Hodgson, 2003). However, actors' search for and selection of new

\footnotetext{
9 'Any technical, procedural, organisational or strategic process or technique used by a firm as part of its normal business activities, for example, its R\&D strategy.' (Foxon, 2003 p.6).
} 
routines is characterized by bounded rationality (Simon, 1959; Nelson and Winter, 1982). Due to factors including imperfect information processing abilities and restricted access to information, economically irrational decisions are made. This sub-optimal decision making sees actors adopting routines that are 'good enough' and provide satisfactory returns, often referred to as 'satisficing' (Simon, 1956).

Bringing these different strands together Grübler (1998) explains that evolutionary processes dictate that socio-technical system change is inherently dynamic, cumulative, systemic and uncertain. Dynamic because energy innovation is characterized by continuous technical change versus long periods of time where technological change is absent. Cumulative because tomorrow's energy innovations are shaped by the characteristics of today's energy technologies, routines etc. (Nelson, 1994). Systemic because energy systems represent large inter-connected systems where small changes can cascade and trigger much bigger changes elsewhere in that system. Uncertain because the highly complex nature of energy systems means we cannot be certain about the future form and diffusion of new innovations.

\subsubsection{Co-evolutionary theory}

A specific strand of evolutionary economic theory emphasises the co-evolutionary nature of system change and how two or more discrete populations can simultaneously shape one or more of the three fundamental mechanisms of each another's evolution: variation, selection and retention (Norgaard, 1994; Murmann, 2003, 2013). In the natural world Thompson (1994) explains how for example some plants and insects have co-evolved, with the plant providing food for the insect, whilst the insect serves to spread the plant's pollen, both positively reinforcing one another's fitness with their selection environment.

This concept has been applied to help explain how the inter-relationships between populations of producers, users, technologies, institutions etc. have shaped non-biological system change (Norgaard, 1994; Murmann, 2003, 2013; Kallis, 2007; Kallis and Norgaard, 2010). Murmann $(2003,2013)$ explains that coevolution can occur for example by influencing the variation processes that give rise to innovations or by shaping the selection environment that determines whether these are adopted.

Building upon Norgaard's (1994) original framework Foxon (2011) presents a coevolutionary framework to help explain transitions to a sustainable low carbon economy. It highlights five key dimensions of a socio-technical system, such as the energy sector, and emphasises the co-evolutionary relationship between these (Figure 9.9): 
- Technologies - systems of methods and designs for transforming matter, energy and information from one state to another in pursuit of a goal or goals

- Ecosystems - systems of natural flows and interactions that maintain and enhance living systems

- Institutions - ways of structuring human interactions

- User Practices - routinized, culturally embedded patterns of behaviour relating to fulfilling human needs and wants

- Business Strategies - the means and processes by which firms organise their activities so as to fulfil their socio-economic purposes

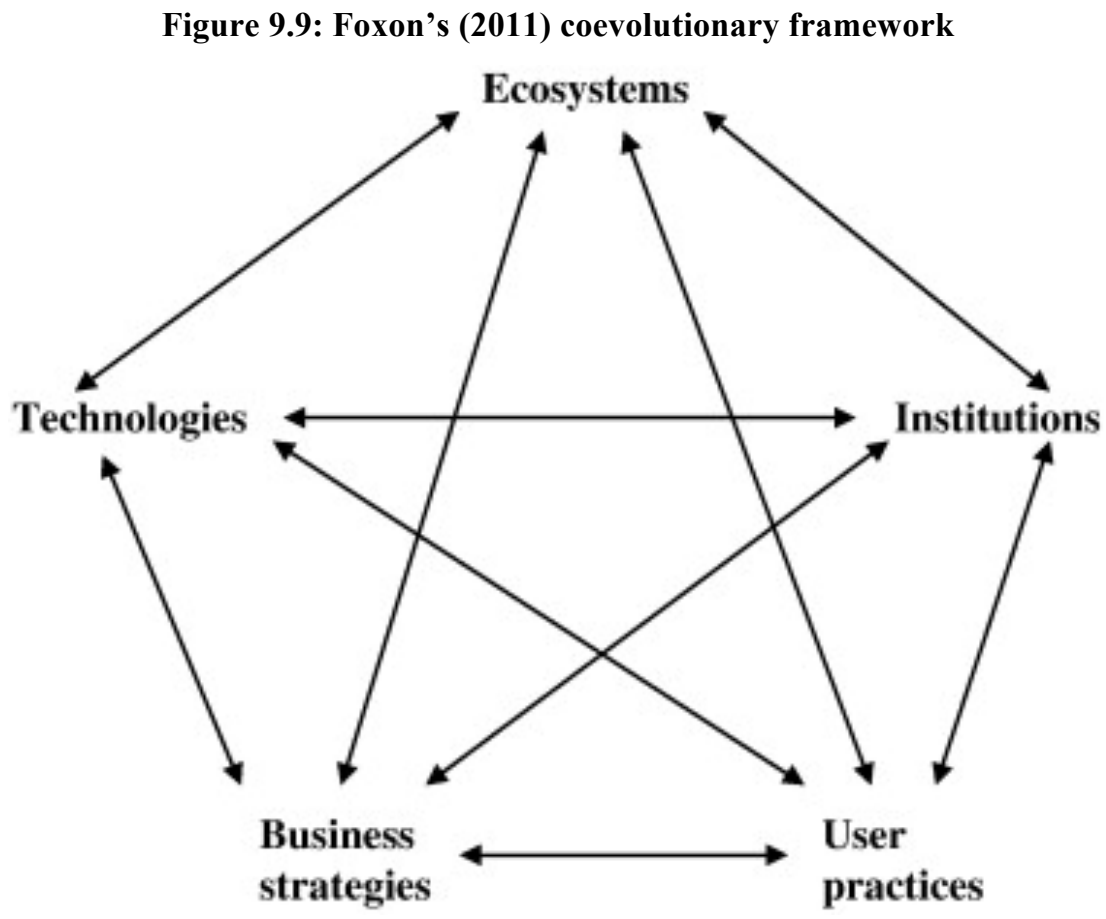

Unlike the socio-technical system approach (Section 0) co-evolutionary frameworks treat each of these sub-systems or domains as systems that evolves under their own dynamics, but who's evolution is simultaneously influencing and influenced by the dynamics of the dimensions through causal interactions (2011).

\subsubsection{Path dependency}

Coevolution across these various dimensions is responsible for shaping system change (van den Bergh et al., 2006). These 'on-going positive feedbacks between components of evolving systems' (Norgaard, 1994 p.82) can result in path-dependency, where 'what happened at an earlier point in time will affect the possible outcomes of a sequence of events occurring at a later point in time' (Sewell, 1996 p.262-3). These feedbacks result in reciprocal causal 
processes that serve to amplify or dampen phenomena (Murmann, 2013), which can in turn intensify small initial differences between firms or technologies over time, and help explain the proliferation of certain innovations over others. In short, history matters when we consider the potential future trajectories of energy system change.

\subsubsection{Technology lock-in}

Path dependency is typically associated with increasing turns to adoption that are responsible for technological (Arthur, 1989) and institutional (Pierson, 2000) lock-in (Section 5.1.3.2). Focusing on technological lock-in, small initial advantages in a technology's design over its rivals can result in a phenomenon termed 'lock-in' grounded in increasing returns where the 'value to a buyer of an extra unit is higher when more units are sold, everything else being equal' (Economides, 2006). In Arthur's (1996) words it relates to 'the tendency for that which is ahead to get further ahead' or why 'that which loses advantage [loses] further advantage' (p.100). Arthur $(1989,1994)$ identifies four distinct types of increasing return that contribute to this effect:

- Scale Economies - Unit costs decline with increasing output as 'sunk costs from earlier investments in production capacity are spread over an increasing production volume in the socio-technical system' (Klitkou et al., 2015 p.24).

- Learning Effects - The accumulation of specialised skills and knowledge through production and market experience results in the product becoming improved or cheaper. Building on work by Arrow (1962) and Rosenberg (1982) this typically takes the form of: (1) 'learning by doing', i.e. the 'productivity gain due to the producer's past production experience’ (Mukoyama, 2006 p.124); (2) 'learning by using', i.e. 'essential aspects of learning that are a function not of the experience involved in producing the product but of its utilization by the final user' (Rosenberg, 1982 p.182); and (3) 'learning by interacting', i.e. the exchange of lessons from learning by doing and learning by using between several parties (e.g. producers and users (Lundvall and Vinding, 2004), which can be re-combined in the development of new products.

- Adaptive Expectations - Increasing adoption of a technology reduces the level of uncertainty surrounding its use, thus potentially reducing the market pull of alternative technologies. This also relates to technological interrelatedness where the adoption of one technology may therefore encourage innovation of complementary technologies as there is less consumer uncertainty surrounding them, as well as technical complementarities (Klitkou et al., 2015). 
- Network Economies - When agents benefit from other agents adopting the same technologies. For example, the more users connected to a telephone network, the greater the scope for communication. Analogous would be a railway network with a greater number of lines and stations, offering more opportunity for transportation.

Various examples of how technologies that gain an early lead from competitors can come to dominate the market have been identified such as the triumph of the VHS video format over BETA-MAX despite neither having a clear technological advantage (Arthur, 1990) or the continued prevalence of pesticide use by farmers, due to 'the heavy initial costs of switching to more sustainable systems and the need for all to act simultaneously in the switching process if economic losses are to be avoided' (Wilson and Tisdell, 2001 p.458).

The case of the QWERTY keyboard design is particularly illuminating (David, 1985). It emerged from a desire amongst typewriter manufacturers to slow down typists fingers as the keys would regularly jam when used by the fastest typists, especially the letters located next to one another. Consequently, typist manufacture Remington sought to slow down its users' typing speed by moving the most frequently used letters further apart, leading to the QWERTY design. The keyboard remains the standard today despite being 10-15\% slower than the optimal keyboard designs because user expectations and skills have become aligned to its design, presenting a major barrier to alternative keyboard designs (Boutellier and Heinzen, 2014).

Turning to the energy sector, increasing returns have also been used to explain the lock-in of energy technologies, such as the dominance of alternating current $(\mathrm{AC})$ over direct current (DC) for electricity networks (David and Bunn, 1988) and the market dominance of the light water nuclear reactor over competing designs, such as heavy water or gas graphite cooled reactors (Cowan, 1990). Cowan points to how the selection of light water reactors by the U.S. Navy for submarine propulsion saw it enjoy a head-start over its rivals, and 'by the time other technologies were ready to enter the market, light water was [already] entrenched' (p. 545).

\subsubsection{Institutional lock-in}

Lock-in can also occur in institutional settings (North, 1990). Pierson (2000) expands upon North's argument and explains that makes political institutions particularly prone to increasing returns due to the following four factors: 
1. The inertia of collective action - 'The consequences of my actions are highly dependent upon the actions of others. What I get depends not just on what I do, but (mostly) on what others do' (p.258).

2. The high density of institutions - 'New institutions and policies are costly to create and often generate learning effects, coordination effects, and adaptive expectations...As social actors make commitments based on existing institutions and policies, their cost of exit from established arrangements generally rises dramatically' (p.259).

3. Using political authority to enhance asymmetries of power - How powerful incumbent actors wield their superior political power to enact changes that further enhance their power; and

4. The intrinsic complexity and opacity of politics - 'It is often very hard to observe or measure important aspects of political performance. And, if we believe that a system is not performing well, it is still more difficult to determine which elements in these highly complex systems are responsible and what adjustments would lead to better results' (p.260)

Focusing on the third of these factors in the context of the energy sector, Hannon's (2012; 2013) research on the energy utility business (EUCo) business model, predicated on vertically integrated and centralised generation and underpinned by volume-sales, shows that the energy utilities have been able to shape the regulatory frameworks to their advantage (

Figure 9.10). This feedback mechanism between business models and political institutions has seen a self-reinforcing relationship between the dominant energy business model and prevailing policy regime. 
Figure 9.10: Positive feedback loop between energy utilities and UK energy regulation (Hannon, 2012)

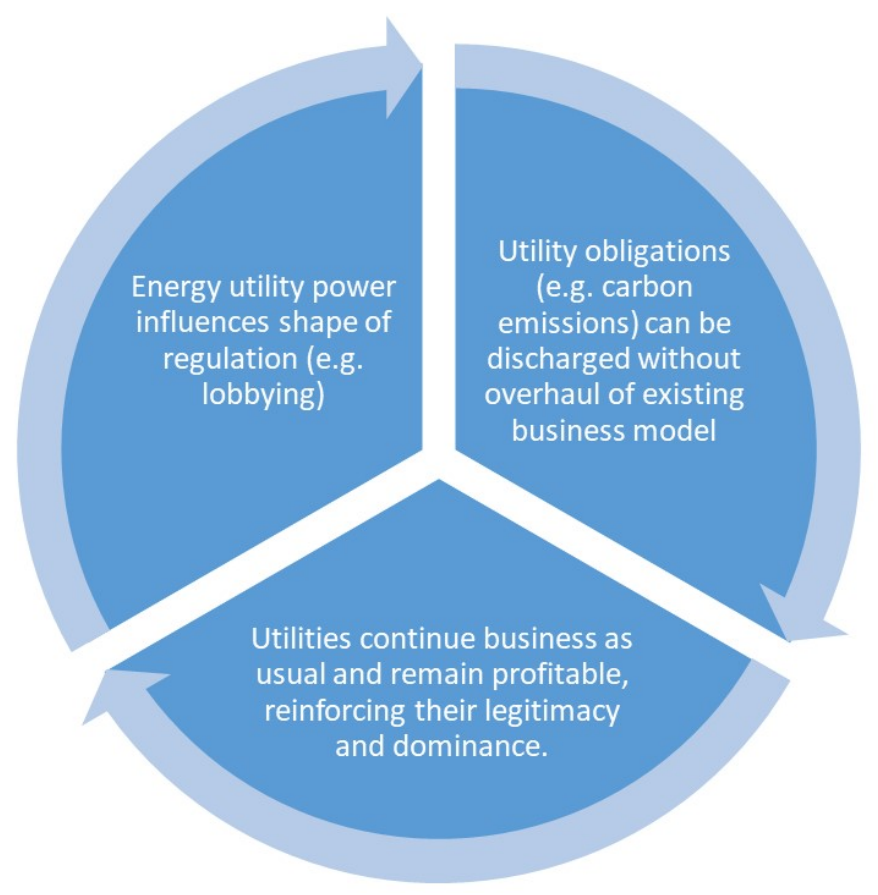

5.1.3.3 Socio-technical system lock-in

Combining these two related concepts of technological and institutional lock-in, Foxon (2011) explains that they can serve to mutually reinforce one another via co-evolutionary processes to create a state of dynamic equilibrium, i.e. a state of balance between continuing processes. Unruh's work $(2000,2002 ; 2006)$ has highlighted how these co-evolutionary processes can lead a particular dynamic equilibrium becoming 'locked-in' and ultimately the status quo. 
Unruh introduces the term the Techno-Institutional Complex (TIC) to describe a system whereby technologies, organisations social norms and political institutions are intimately inter-linked and causally influence one another's evolution. These reinforce one another in a self-referential manner, resulting in a system that is highly resistant to disruption and able to persist in the face of threats from low-carbon variations. He presents one example of the persistence of the automobile-based transport network (Figure 9.11). Here there is a positive feedback between technological, institutional and social system dimensions where expanding the road network (technological), encourages more people to drive (social) and this results in greater tax receipts from drivers (institutional), which then enables further road maintenance and expansion. Unruh uses his TIC framework to explain how centralised fossil fuel energy system have remained dominant despite the threat from decentralised, low-carbon energy alternatives. We expand upon path dependency and lock-in in the energy sector in Box 9.2.

Figure 9.11: An illustration of the techno-institutional complex that fosters lock-in in automobile-based transportation networks (Unruh, 2000)

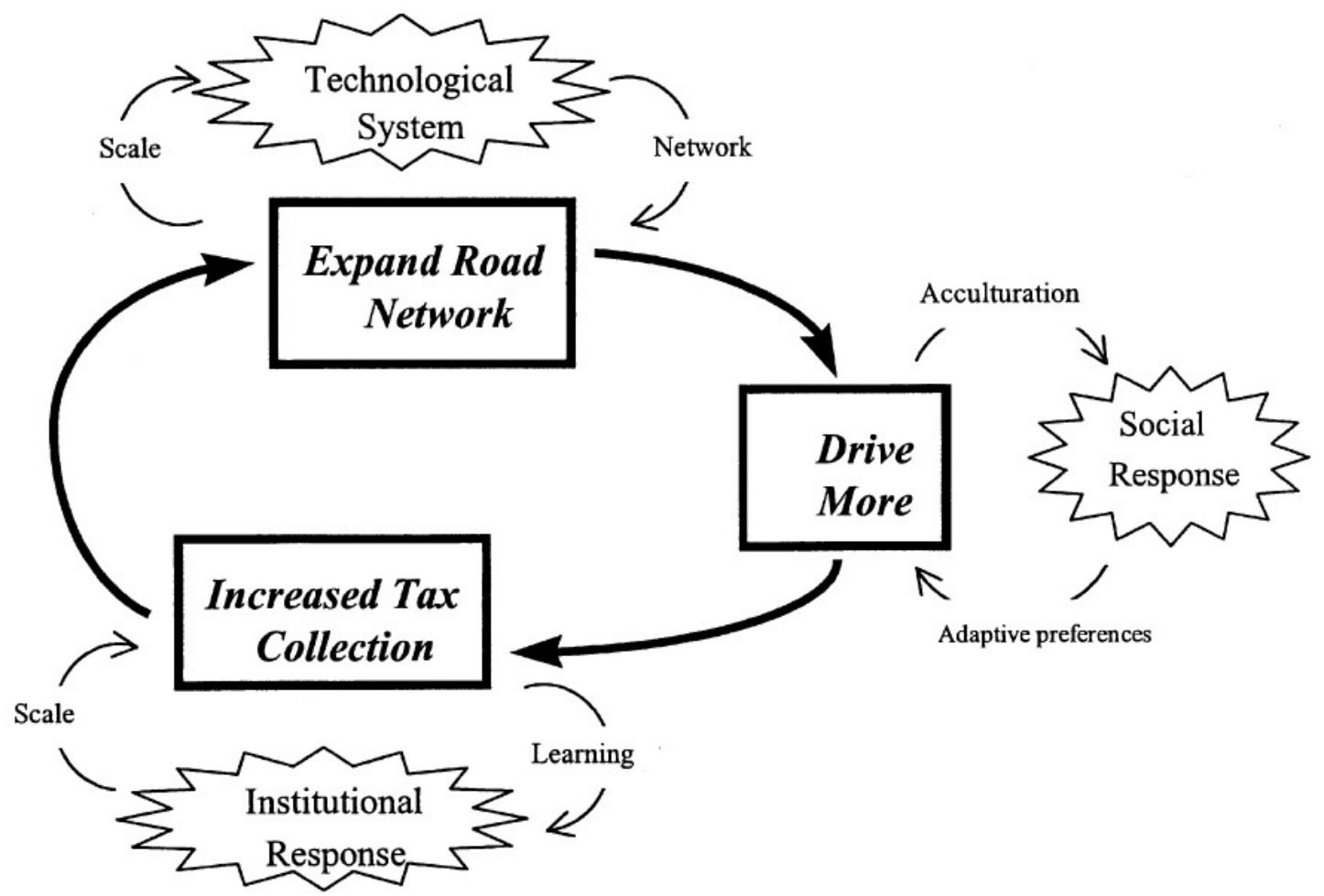




\section{Box 9.2 - Energy sector path-dependency: Long-run and slow-burn transitions}

Historically there have been some examples for surprisingly swift energy system transitions. Examples include the dramatic increase in crude oil's share of Japan's primary energy (6\% in 1950 to $72 \%$ by 1970 ), natural gas's share of the Netherlands' primary energy ( $5 \%$ in 1965 to $46 \%$ in 1975) (Smil, 2010b) or wind's share of Denmark's total electricity supply (2\% in 1996 to 49\% in 2015) (IEA, 2017). However, these are considered to be exceptions to the rule that energy system change is path-dependent and thus inherently slow and dictated by past events. Furthermore, whilst 'change of individual technologies via substitution can happen quickly...change of entire technology systems, i.e. the diffusion of complex sets of interrelated technologies, infrastructures, and institutions is inevitably a lengthy process (Grubler, Wilson and Nemet, 2016 p.20).

Energy historian Roger Fouquet identifies that from invention to wide-spread diffusion has historically taken on average 100 years in the energy sector, with diffusion alone lasting around 50 years (Fouquet, 2010). For example, it took more than 100 years before coal became a leading energy source in Europe and North America, usurping traditional biofuels (e.g. wood) (Smil, 2010b; Kander, Malanima and Warde, 2013). Similarly Bento \& Wilson (2016) found that the formative phase for both energy and non-energy technologies lasted approximately 22 years, with another finding a longer average period of 39 years for a similar group of technologies (Gross et al., 2018).

Radical energy technological innovations are typically subject to longer formative phases because they: (1) must undergo an extended period of RD\&D; (2) have to achieve acceptance amongst human actors by building legitimacy; and (3) may lack compatibility with wider structural elements, potentially requiring upgraded or fundamentally different infrastructure to facilitate adoption (Grubler, Wilson and Nemet, 2016).

The capital intensiveness of energy technology investments and the longevity of capital stock is

\subsection{What frustrates or enables energy innovation? Insights from innovation systems}

Unlike the other two approaches examined in this section the innovation systems perspective provides a highly targeted and pragmatic approach to identifying the drivers and barriers of innovation. It is much less concerned with the dynamics of energy system transformation and more about practical ways of accelerating innovation, with relatively little thought about the implications of innovation on the wider energy system. We begin with an introduction of how innovation unfolds in a non-linear fashion (Section 5.2.1), before outlining the innovation 
systems approach in full; it's different scales of analysis and examples of its application to energy studies (Section 5.2.2).

\subsubsection{Chain-linked model of innovation}

The 'innovation journey' was originally conceived as a continuous and linear process, whereby basic research was followed by applied development, demonstration and diffusion (Gallagher et al., 2012). This linear model placed a strong emphasis on the influence of both demand and supply sides for driving technological innovation (Foxon, 2003; Weber and Truffer, 2017), giving rise to the related concepts of demand pull and supply push drivers of innovation (Bush, 1945; Griliches, 1957; Schmookler, 1966). Supply push relates to the process of providing more resource to generate new knowledge, which can 'push' new technologies through to market, whilst demand pull stimulates innovation by generating a demand for a new type of product or service. Figure 9.12 outlines various examples of different mechanisms to accelerate energy innovation, with supply push clustered to the left hand side and demand pull to the right (IEA, 2015).

Figure 9.12: Tailoring innovation support to reflect technological and market maturity (IEA, 2015)

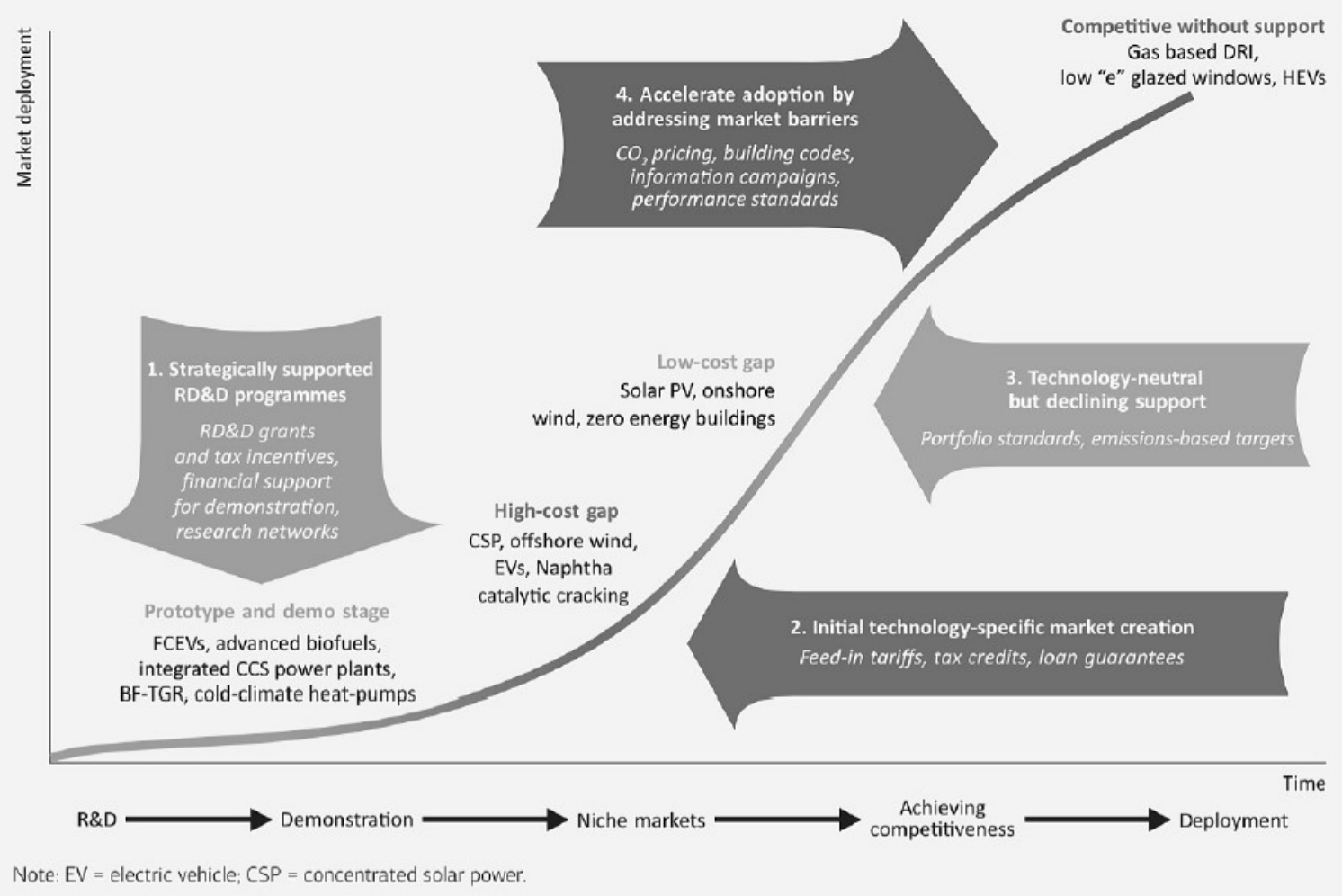

Today, it is widely understood that innovation does not necessarily proceed in a linear fashion and that the stages of the innovation process are instead linked, with feedbacks between each stage (Kline and Rosenberg, 1986; Brooks, 1995) (Figure 9.13). These 
feedbacks are the results of 'failures that occur at various stages may lead to reconsideration of earlier steps, and this may eventually lead to totally new innovations' (Fagerberg, 2003 p.19). For example, the first time an energy technology is tested at full-scale technical issues may arise that had not previously been identified at smaller scale but which warrants revisiting earlier stage $\mathrm{R} \& \mathrm{D}$ in order to resolve. The non-linear model also acknowledges that innovation is shaped by influences that stretch beyond the boundaries of the firm laid the foundations for a systems-level perspective on innovation: innovation systems.

Figure 9.13: Chain-lined non-linear innovation chain (adapted from Wilson and Grübler, 2014)

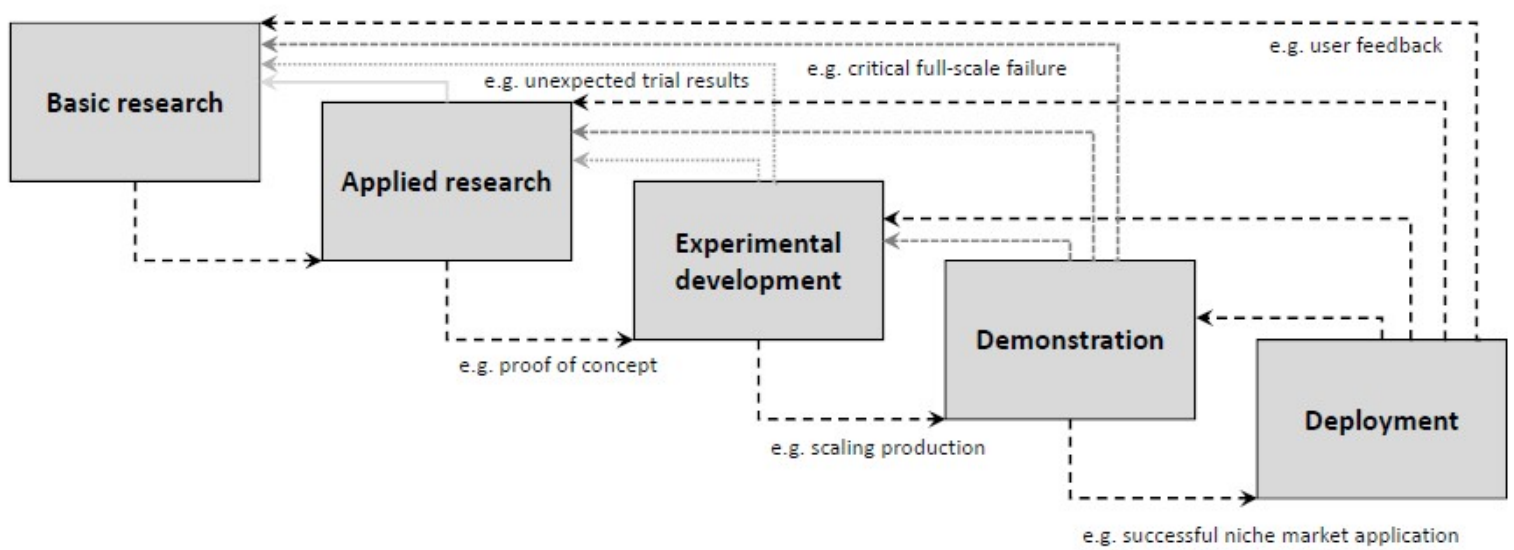

\subsubsection{Innovation systems}

An innovation system incorporates the 'determinants of innovation processes; all [the] important economic, social, political, organisational, institutional, and other factors that influence the development, diffusion, and use of innovations' (Edquist, 2006 p.182). The overarching logic of is that innovation is a product of actors interacting with their wider environment, which is comprised of other actors, networks, institutions and technologies (Lundvall, 1992). It also highlights the evolutionary nature of the innovation process (Section 5.1), paying special attention to the creation of variations and how these are subsequently selected and replicated by their wider environment (Lundvall, 2007), as well as the cumulative nature of innovation systems that are built up over very long periods of time (Nelson, 1993).

The approach has been applied to various different units of analysis, each emphasising a distinctly different scales and boundaries (see Box 9.3). However, we focus on the Technology Innovation System (TIS) framework and discuss how it has been applied to energy studies. 


\section{Box 9.3 - Variants of the innovation system approach}

National innovation system (NIS) - Pioneered by Chris Freeman (1987), an NIS represents 'the network of institutions in the public and private sectors whose activities and interactions initiate, import, modify and diffuse new technologies'. The approach emerged from a desire to understand whether countries' differences in innovation performance could be attributed to their characteristics, such as prevailing institutions, natural resources, human capital, infrastructure etc., which have built up over a prolonged period of time (Nelson, 1993; Andersen and Lundvall, 1997). Freeman (1987) applied the NIS framework to help explain why Japan had emerged as global economic power during mid to late $20^{\text {th }}$ Century, arguing its success was owed to national characteristics including: (1) a long-term strategy to foster innovation; (2) an abundant high-quality workforce; (3) knowledge exchange flows between industrial actors via conglomerates or keiretsus; (4) an emphasis on complementary non-technological innovations (e.g. 'just-intime' manufacturing); and (5) a capacity to reverse engineer and improve on technology imports.

Regional innovation system (RIS) - Similar to the NIS approach but with a focus on regions rather than nations (Cooke, Gomez Uranga and Etxebarria, 1997). Examples might include Silicon Valley in the US for ICT or Silverstone Park in the UK for automotive industry.

Sectoral innovation system (SIS) - Adopts a sectoral focus, centred on the 'set of products and the set of agents carrying out market and non-market interactions for the creation, production and sale of those products. A sectoral systems has a specific knowledge base, technologies, inputs and demand' (Malerba, 2002 p.247).

Global innovation system (GIS) - Growing international linkages between geographically isolated places following globalisation has meant that territorial boundaries have become increasingly blurred (Binz and Truffer, 2017). This has led to the emergence of the GIS as an umbrella of numerous discrete regional and/or national innovation systems (Carlsson, 2006; Binz and Truffer, 2017). 


\subsubsection{Technology innovation systems}

An offshoot of the innovation systems literature examines technology innovation systems (TIS), for which the analytical focus is the technology, which may cross geographical and sectoral boundaries. A TIS can be defined as 'a network or networks of agents interacting in a specific technology area under a particular institutional infrastructure to generate, diffuse, and utilise technology' (Carlsson and Stankiewicz, 1991 p.94). It is comprised of a variety of core elements that perform a host of different functions that support technology innovation. Mapping the structure of a TIS helps to identify the presence and characteristics of key structural components before determining their capacity to stimulate innovation (Wieczorek and Hekkert, 2012). These are broadly split across four dimensions (Hekkert et al., 2011; Jacobsson and Karltorp, 2013):

- Actors - the organisations responsible for developing, diffusing and implementing new technologies, most commonly education institutes (e.g. universities), industry and market actors (e.g. technology developers, suppliers, customers), public bodies (e.g. regulators, government departments) and supporting organisations (e.g. venture capitalists).

- Institutions - the 'rules of the game' that characterise actors' behaviour, expectations and values (North, 1990). These include formal institutions (e.g. regulations, laws) and informal institutions (e.g. routines, expectations).

- Networks - these connect actors and shape their activities, for example, through coordination and knowledge exchange. They typically centre upon scientific, industrial or governmental actors, or a combination of these. Examples include trade associations or research networks.

- Technology and infrastructure - the technological systems and infrastructural networks that facilitate technology innovation. These commonly include test facilities, complementary technologies and distribution/transmission networks (Bolton and Foxon, 2015)

\subsubsection{TIS evolution}

A fully-functioning innovation system does not simply appear overnight. Bergek et al. (2008) identify three phases of TIS structural development: formation, growth and stability, a similar sequence to that outlined by Hekkert et al. (2011) of pre-development, development, take-off, acceleration and stabilization. During the formative phase few the structural components of 
the TIS are in place and this period sees 'the constituent elements evolve and agglomerate through entry of firms and other organisations, formation of networks, institutional alignment and the accumulation of knowledge and physical artefacts' (p.577). The process is characterised by uncertainty and can last many decades (Kemp, Schot and Hoogma, 1998). The next stage is the growth phase, characterised by positive feedbacks that see a selfsustained growth of the TIS and its functions, and then the stability phase, a period characterised by a stable structure that is largely resilient to external forces (Bergek, Jacobsson and Sandén, 2008). This last phase can also lead to lock-in due to positive feedback mechanisms, and whilst this can maintain the dominance of the TIS it can constrain the technology's development along a rigid trajectory. This can in turn limit the potential for the TIS to continue to evolve, for example incorporating new actors with new idea that may drive the continued improvement of the technology.

This perspective on TIS evolution does not account for TIS degradation and reformation. Consequently, Markard (2018) recently presents a decline phase, signalling the disintegration of a TIS. This may eventually lead the technology to cease existing or to persist only through niche applications. Structurally a TIS's decline may manifest itself in several ways, such as institutional dis-alignment, the withdrawal of key TIS actors and a break-up of critical networks. The positive feedbacks that once helped the TIS to become entrenched can now fuel vicious circles that accelerate its decline. For example, the withdrawal of actors diminishes the political capital necessary to secure valuable resources, such as via political lobbying. This may result in a less than ideal institutional environment, precipitating the further withdrawal of key actors. Consequently, a TIS may not necessarily move through all of the phases earlier identified if it prematurely enters its decline phase (Bergek et al., 2008; Markard, 2018).

Building on this Hannon et al. (2018) point to how a TIS may undergo more nuanced phases, such as stagnation, revitalisation and reconfiguration during its evolution (Hannon, Van Diemen and Skea, 2018). Furthermore, a TIS 'fast-tracking' ${ }^{10}$ through certain stages (e.g. formation) due to phenomena such as technological leapfrogging ( $\mathrm{Hu}$, Skea and Hannon, 2017) (see Box 9.5).

\footnotetext{
${ }^{10}$ Here the formation phase still occurs but is significantly accelerated by its ability to draw on knowledge and resources from elsewhere.
} 


\subsubsection{TIS functions}

TIS functions were developed to help diagnose the performance of an innovation system, highlighting the causal mechanisms between structure and performance (Jacobsson and Karltorp, 2013). They help analysts scan the innovation system and identify systemic weaknesses, with a view to staging interventions to improve innovation performance (Smits and Kuhlmann, 2004; Markard and Truffer, 2008). In essence, if a TIS's functions are all performing strongly then, assuming basic viability of the technology, it should steadily progress towards commercialisation. Each TIS function represents a specific interaction between structural components that has a positive bearing on the development, deployment and adoption of emerging technology (A. Johnson and Jacobsson, 2000; Edquist, 2001; Hekkert and Negro, 2009). These are outlined in Table 9.2 following a review of the literature (Kemp, Schot and Hoogma, 1998; Hekkert et al., 2007; Bergek et al., 2008; Hekkert and Negro, 2009; Suurs and Hekkert, 2009; Jacobsson and Bergek, 2011; Jacobsson and Karltorp, 2013; Bento and Wilson, 2016)

Table 9.1: Description of TIS functions

\begin{tabular}{|l|l|}
\hline Function & Description \\
\hline $\begin{array}{l}\text { F1 - Knowledge } \\
\text { development }\end{array}$ & $\begin{array}{l}\text { The creation of technological variety achieved by a broadening and deepening of a codified } \\
\text { knowledge } 11 \text { base via research and development (R\&D). }\end{array}$ \\
\hline F2 - Knowledge exchange & Exchange of information between actors facilitated by inter-actor networks. \\
\hline $\begin{array}{l}\text { F3 - Entrepreneurial } \\
\text { experimentation }\end{array}$ & $\begin{array}{l}\text { Entrepreneurs recognise the latent value proposition of emergent technologies and seek to realise } \\
\text { this potential via commercial experiments. These experiments typically generate a form of tacit } \\
\text { knowledge and in turn reduce the degree of uncertainty associated with a technology, either } \\
\text { through success or failure. }\end{array}$ \\
\hline $\begin{array}{l}\text { F4 - Guidance of the } \\
\text { search }\end{array}$ & $\begin{array}{l}\text { Pressures that encourage actors to enter a technological field and subsequently guide the stage and } \\
\text { focus of innovation activities they undertake, such as policy targets and technology roadmaps. }\end{array}$ \\
\hline F5 - Resource mobilisation & $\begin{array}{l}\text { Mobilisation of financial, human and physical resources critical to the technology innovation } \\
\text { process. }\end{array}$ \\
\hline
\end{tabular}

11 'Codified knowledge means reproducible, transparent, accessible knowledge documented or enshrined in blueprints, manuals, or sets of instructions' (Wilson and Grübler, 2014 p.17) 


\begin{tabular}{|l|l|}
\hline F6 - Market formation & $\begin{array}{l}\text { Mechanisms that create niche markets or 'protected spaces' enabling technologies to compete } \\
\text { against initially superior incumbent technologies in order to boost levels of adoption, such as } \\
\text { favourable tax regimes or new industry standards. }\end{array}$ \\
\hline F7 - Legitimation & $\begin{array}{l}\text { The act of granting legitimacy to an emerging technology by strengthening its 'fitness' with the } \\
\text { prevailing institutional regime. TIS actors seek to achieve this by shaping existing institutions to } \\
\text { galvanise support for this new technology amongst actors, for example via political lobbying. }\end{array}$ \\
\hline
\end{tabular}

TIS functions are inter-dependent and so changes in one function can induce changes in another. In this sense innovation systems co-evolve and are subject to positive feedback or virtuous cycles, which can mean that the poor performance of just one function could result in 'system failure', and vice versa (Carlsson and Jacobsson, 1997; Coenen and Diaz Lopez, 2010; Jacobsson and Karltorp, 2013).

Hekkert et al. (2007) highlight one such example of a feedback, where growing firms engaged in experimentation (F3) begin to lobby for conditions preferential to their organisation's operations (F4) in order to gain more legitimacy (F7) and resources (F5) to support its continued growth. If they are successful then their business is likely to grow, affording them greater power to lobby other system actors in order to cultivate even more favourable market conditions for their own business operations. Suurs (2009) identifies another where knowledge generated via research (F1) yields negative results, in turn reducing confidence in the emerging technology amongst key stakeholders (e.g. policy makers) (F7), encouraging them to shift their attention elsewhere (F4). This could see a reduction in funding of that technology (F5) further reducing the likelihood of successful research (F1). In response to the criticism that TIS studies have typically relied on ex-post qualitative analysis of innovation system performance (Jacobsson and Bergek, 2011; Grubler, 2014) various indicator frameworks have been developed to quantitatively assess the performance of energy innovation systems have emerged (Hillman et al., 2011; Klitkou, Iversen and Borup, 2012; Borup et al., 2013; Wilson, 2014; Bento and Wilson, 2016; Hu, Skea and Hannon, 2017; Miremadi, Saboohi and Jacobsson, 2018a, 2018b).

Table 9.2 synthesizes these to present an non-exhaustive selection of indicators, each paired with a specific function. 
Table 9.2: Indicators used to measure energy innovation system functions

\begin{tabular}{|c|c|}
\hline TIS Function & Indicator \\
\hline \multirow{4}{*}{$\begin{array}{l}\text { Knowledge } \\
\text { Development (F1) }\end{array}$} & Number of R\&D projects (count) \\
\hline & Scientific publications (count) \\
\hline & Patent applications (count) \\
\hline & Patent citations (count) \\
\hline \multirow{4}{*}{$\begin{array}{l}\text { Knowledge } \\
\text { Exchange (F2) }\end{array}$} & Number and breadth of formal international networks (count) \\
\hline & Number and breadth of scientific and/or industry networks (count) \\
\hline & Number of joint science-industry projects (count) \\
\hline & Number of public-private co-publications (count) \\
\hline \multirow{4}{*}{$\begin{array}{l}\text { Entrepreneurial } \\
\text { Experimentation } \\
\text { (F3) }\end{array}$} & Concentration of investment in a dominant design (share of technology RD\&D \$) \\
\hline & Number of technology developers (count) \\
\hline & Unit capacity of technology (MW) \\
\hline & Levelised cost of technology ( $\$ / \mathrm{MWh})$ \\
\hline \multirow{2}{*}{$\begin{array}{l}\text { Guidance of the } \\
\text { Search (F4) }\end{array}$} & Number and ambition of government or industry targets (count) \\
\hline & Number and ambition of roadmaps or innovation needs assessments (count) \\
\hline \multirow{5}{*}{$\begin{array}{l}\text { Resource } \\
\text { Mobilisation (F5) }\end{array}$} & RD\&D expenditure $(\$)$ \\
\hline & Investment is scientific infrastructure (such as state labs, test facilities) (\$) \\
\hline & RD\&D personnel (count) \\
\hline & Asset finance $(\$)$ \\
\hline & Market-based subsidies (\$) \\
\hline \multirow{2}{*}{$\begin{array}{l}\text { Market Formation } \\
\text { (F6) }\end{array}$} & Installed capacity (MW) \\
\hline & Power generation (TWh) \\
\hline
\end{tabular}




\begin{tabular}{|c|c|}
\hline & Royalty and license fees (\$) \\
\hline & Job creation (count) \\
\hline & Technology exports $(\$)$ \\
\hline \multirow[t]{4}{*}{ Legitimation (F7) } & Membership of trade associations (count) \\
\hline & $\begin{array}{l}\text { Government support for technology (e.g. frequency of positive references in white papers, } \\
\text { parliamentary debates etc.) (count) }\end{array}$ \\
\hline & Public support for technology (\% share of public) \\
\hline & Number and scope of environmental standards and certifications (count) \\
\hline
\end{tabular}

\subsubsection{TIS blocking and inducement mechanisms}

Fulfilled functions are a sign of strength across one or more structural dimensions, whilst unfulfilled system functions are a manifestation of structural weaknesses. These are known respectively as inducement or blocking mechanisms (Bergek, Hekkert and Jacobsson, 2008; Hekkert et al., 2011; Jacobsson and Karltorp, 2013; Patana et al., 2013). The latter are typically linked to the absence or poor quality of structural elements (Wieczorek and Hekkert, 2012). Woolthuis et al. (2005) explain that function related failures fall into four broad categories: institutional, infrastructural, interaction and capabilities, the latter referring to a lack of actors' competencies and/or resources to innovate.

These mechanisms can be endogenous or exogenous to the TIS, i.e. emanating from within or outside the TIS (Bergek, Hekkert and Jacobsson, 2008; Smith and Raven, 2012; Jacobsson and Karltorp, 2013; Markard, Hekkert and Jacobsson, 2015). Consequently, efforts have been made to identify how technology innovation is shaped by the influence of its technological, sectoral, geographical and political contexts (Jacobsson and Karltorp, 2013; Bergek et al., 2015; Kern, 2015). To help illustrate these we take examples taken from Hannon et al.'s (2017) study of UK marine energy innovation:

- Technological - how technologies complement, compete and interact with one another. For example, advances in wind power have been critical in offering knowledge spill-overs and boosts in legitimacy of tidal stream, given the similarity across dominant designs. 
- Sectoral - sectoral actors, institutions, networks and infrastructures are typically shared across numerous technologies, exerting an influence over these. For example, marine energy RD\&D funding is managed by government energy departments that have to make decisions about how to balance funding for wave and tidal with a widerange of other emerging technologies (e.g. floating wind, carbon capture, utilisation and storage (CCUS), batteries etc.).

- Geographical - the influence of space and place on technology innovation. For example, the concentration of both wave and tidal stream power off the North West coast of the UK has contributed to Scotland becoming the epicentre for marine energy innovation.

- Political - how high-level political developments and actors' political agency shape a technology's development. For example, the renaissance in UK marine energy was underpinned by international political developments, most notably to move towards tackling climate change, as well as the devolution of powers from UK to Scottish government that offered Scotland more control over developing a domestic industry.

We present a detailed list of commonly identified specific blocking mechanisms below, categorised by their relevant TIS structural pillars and coupled with their associated functions (Table 9.3) (Smith, 2000; Johnson and Jacobsson, 2001; Bogenrieder and Nooteboom, 2002; Woolthuis, Lankhuizen and Gilsing, 2005; Bergek et al., 2008; Bergek, Hekkert and Jacobsson, 2008; Jacobsson and Bergek, 2011; Jacobsson and Karltorp, 2013; Darmani et al., 2014).

Table 9.3: Overview of common TIS functions blocking mechanisms against structural dimensions

\begin{tabular}{|l|l|l|}
\hline \multirow{2}{*}{$\begin{array}{l}\text { TIS structural } \\
\text { dimension }\end{array}$} & Blocking mechanisms & TIS functions \\
\hline \multirow{2}{*}{ Actors } & Poorly articulated demand of new products/services by customers & F4 - Guidance of the search \\
\cline { 2 - 4 } & Lack of capacity amongst firms to learn rapidly and effectively & F1 - Knowledge development \\
\cline { 2 - 4 } Institutions & $\begin{array}{l}\text { Under-developed supply chain } \\
\text { Absence of supportive regulation that serves to 'level the playing } \\
\text { field' between emerging and incumbent technologies (e.g. standards, } \\
\text { taxes, subsidies) }\end{array}$ & F5 - Resource mobilisation \\
& \begin{tabular}{l} 
Lack of cultural emphasis on value of entrepreneurship \\
\cline { 2 - 4 }
\end{tabular} & F7 - Legitimation \\
\hline
\end{tabular}




\begin{tabular}{|c|c|c|}
\hline & $\begin{array}{l}\text { Short-term planning horizons, risk averseness and strong emphasis on } \\
\text { short pay back periods for investments }\end{array}$ & F5 - Resource mobilisation \\
\hline & Culture of collaboration and sharing of resources & F2 - Knowledge exchange \\
\hline \multirow[t]{3}{*}{ Networks } & $\begin{array}{l}\text { Poorly developed learning networks undermine collaboration and } \\
\text { cross-fertilisation }\end{array}$ & F2 - Knowledge exchange \\
\hline & $\begin{array}{l}\text { Over developed learning networks see actors becoming inward- } \\
\text { looking and ignoring external development }\end{array}$ & F1 - Knowledge development \\
\hline & Weak political networks of new entrants versus incumbents & $\begin{array}{l}\text { F5 - Resource mobilisation } \\
\text { F7 - Legitimation }\end{array}$ \\
\hline \multirow{3}{*}{$\begin{array}{l}\text { Technology and } \\
\text { Infrastructure }\end{array}$} & Insufficient test infrastructure to support technology experimentation & F1 - Knowledge development \\
\hline & $\begin{array}{l}\text { Lack of high-speed ICT infrastructure, broadband, telephone, energy } \\
\text { supply, etc. to enable communication }\end{array}$ & F2 - Knowledge exchange \\
\hline & $\begin{array}{l}\text { Extensive and well-functioning transportation system to enable flow } \\
\text { of human capital }\end{array}$ & F5 - Resource mobilisation \\
\hline
\end{tabular}

For the structural dimension of networks we take the worked example below (Figure 9.14) that considers how the formal requirement for publicly funded energy RD\&D projects to include multiple partners impacts upon inter-actor collaboration. This rule can help support collaboration and in turn knowledge exchange (F2) through building inter-actor networks, as well as help actors share complementary human and financial resources (F5). By sharing information, actors can also agree upon shared innovation priorities that inform the guidance of the search (F5). The absence of this rule can serve to undermine all three of these functions. 


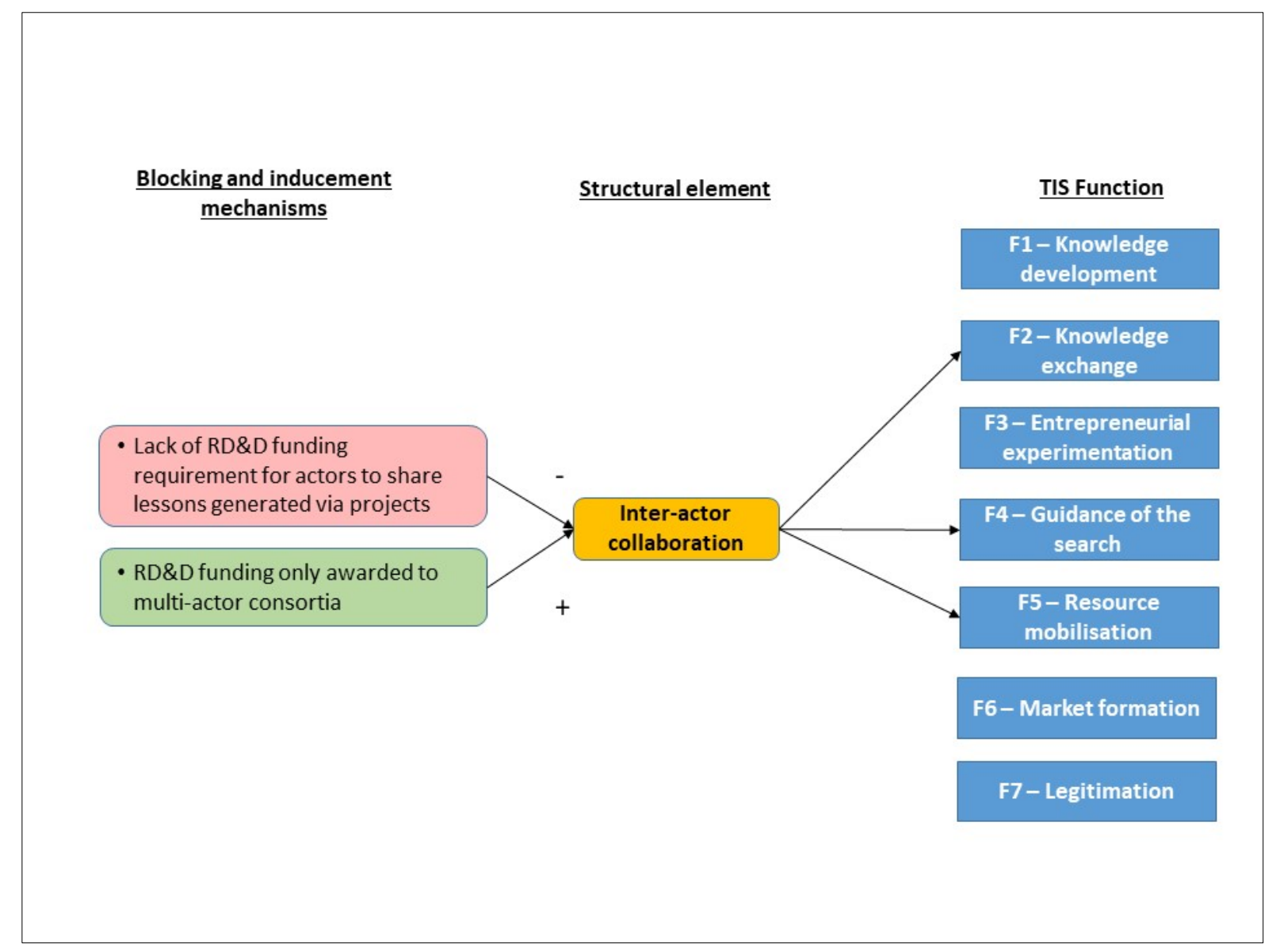

5.2.3.4 Applications of TIS framework to energy studies

The TIS framework has been applied to a wide range of energy related studies. These have examined the drivers and barriers associated with energy technologies such as wind power (Bergek and Jacobsson, 2003; Kamp, Smits and Andriesse, 2004; Gosens and Lu, 2013; Jacobsson and Karltorp, 2013; Reichardt et al., 2016; Hu, Skea and Hannon, 2017; Karltorp, Guo and Sandén, 2017), solar PV (Jacobsson, Sandén and Bangens, 2004; Dewald and Truffer, 2011; Quitzow, 2015), solar thermal (Nemet, 2014), biofuels (Hillman et al., 2008; Suurs and Hekkert, 2009; Meyer et al., 2014), biomass (Negro and Hekkert, 2008), combined heat and power (CHP) (Hekkert, Harmsen and de Jong, 2007; Hawkey, 2012), nuclear (Grubler, 2014) and marine energy (Vantoch-Wood, 2012; Corsatea, 2014; Andersson et al., 2017; Hannon, Van Diemen and Skea, 2017). We offer a detailed overview of one such study in Box 9.4. 


\section{Box 9.4 - Examining wave energy's slow route to market in the UK}

Almost 20 years after the UK's first wave energy innovation programme came to an end in the 1980 s, a new programme to accelerate wave energy innovation was launched. Despite almost $£ 200 \mathrm{~m}$ of public funds being invested in UK wave energy innovation since 2000, it remains some distance away from commercialisation. Adopting a TIS framework the research examined the extent to which the failure to deliver a commercially viable wave energy device can be attributed to weaknesses in both government and industry's support for wave energy innovation in the UK. Both quantitative (e.g. patents, bibliometrics, public RD\&D grants) and qualitative (e.g. expert interviews, documentary evidence) data were analysed.

The research finds that wave energy's failure to reach market can, in part, be attributed to weaknesses in government and industrial strategy to support wave energy innovation in the UK, most notably a premature emphasis on commercialisation and a lack of knowledge exchange between firms. This is evidenced by a poor performance against indicators such as a reduction in active firms (e.g. Pelamis), a fall in installed and rated capacity of devices, and a lack of convergence around a dominant device design.

To address this poor performance a concerted effort from the public sector to learn from past policy mistakes via knowledge capture initiatives, led primarily by the Scottish Government. A reconfiguration of the UK's wave energy innovation system followed, including the: re-design of RD\&D programmes, formation of new actor networks and commissioning of world-class test

The geographical focus of TIS energy studies has typically focused on Western Europe and North America, with relatively little focus on the developing world. Notable exceptions include studies of energy technologies in China (Gosens and Lu, 2013; Hu, Skea and Hannon, 2017; Karltorp, Guo and Sandén, 2017), India (Edsand, 2016) and Brazil (Meyer et al., 2014). In this context the TIS framework has been criticised for being constructed from a developed country perspective without acknowledging the fundamentally different characteristics of developing countries (Edsand, 2016).

One important difference is that developing world energy TISs are emerging in countries that have become industrialised relatively recently versus developed countries, having an important bearing on their innovation capacity. However, in such a globalised world, developing countries are able to leverage advances achieved in developed countries. This term is often known as technologically leapfrogging (Tukker, 2005; Gallagher, 2006; Binz et 
al., 2012), where a nation takes advantage of the lessons learnt by developed countries and implements these to deliver better performing systems of production and consumption, in turn overtaking the established industries and becoming a new industry leader. This concept has been tested against the case of China's wind energy sector with contrasting findings (Box 9.5).

\section{Box 9.5 - China: Technological leapfrog or laggard? The case of wind power.}

Some scholars find that China has leapfrogged many leading countries in terms of wind power innovation but still lags behind a handful of the industry leaders (Ru et al., 2012). Others identify more of a mixed set of results with China beginning 'to lead across a range of innovation inputs (e.g. R\&D expenditure) and outputs (e.g. publications) but lags considerably behind international competitors against other output and outcome indicators such as patents, revenue and exports' (Hu, Skea and Hannon, 2017 p.227). In contrast other studies have found that China continues to rely on foreign technology (Klagge, Liu and Campos Silva, 2012; Zhao et al., 2012; Gosens and Lu, 2013), such as core components like high-quality steel bearings and control systems.

Hu et al. (2017) explain that China's innovation performance has steadily improved as it has made great strides towards improve its innovation capabilities by acquiring technological 'know-how' including technology licensing and mergers and acquisitions of developed country firms, such as Goldwind's acquisition of Germany's Vensys in 2008. China has also to put in place other key innovation system components such as regulations (e.g. Renewable Energy Law), actors (e.g. wind turbine manufacturers) and infrastructure (e.g. state laboratories and test facilities).

\subsubsection{Energy technology innovation system}

Emphasising the need for a system-level examination of energy innovation processes and some unique characteristics of the energy sector that characterise energy innovation processes Wilson \& Grübler (2014) presented their concept of the Energy Technology Innovation System (ETIS) framework (Figure 9.15). In contrast to the TIS framework it emphasises four different structural dimensions: resources, knowledge, adoption and use and actors and institutions. Unlike the TIS framework they align these dimensions alongside a chain-linked innovation process, emphasising that in order for the technology to progress towards diffusion then each of these dimensions will gradually strengthen, such as an accumulating 
knowledge stock. Conversely, these dimensions may also diminish, such as an eroding knowledge stock at the hands of knowledge depreciation. Finally, the framework emphasises positive feedbacks inherent in the innovation process such as the economies of scale - as adoption grows unit costs can fall - that in turn encourage greater adoption and further reductions in costs.

Figure 9.15: Energy technology innovation system framework (Wilson and Grübler, 2014)

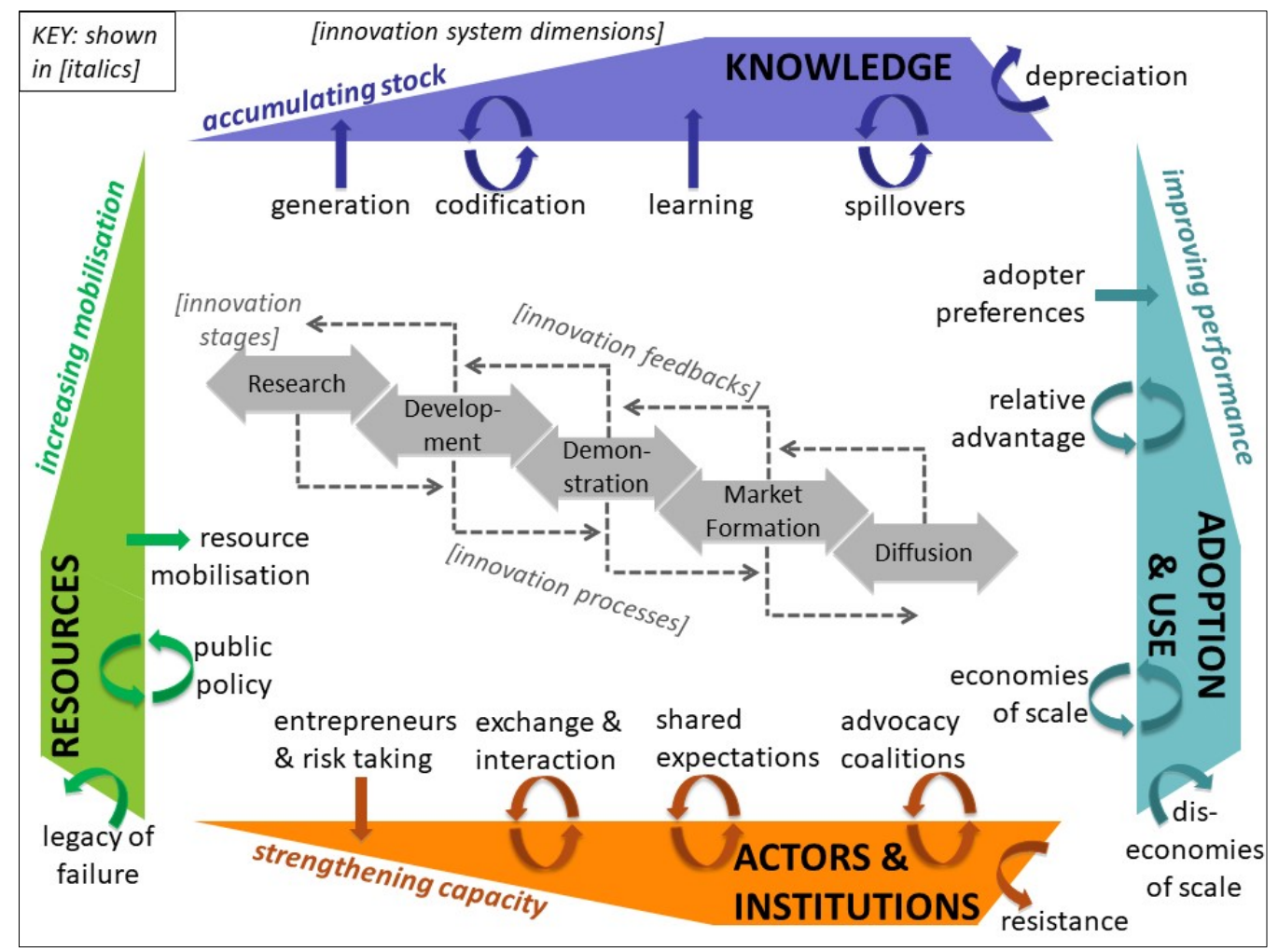

\subsection{How and why do energy systems transform? Insights from socio-technical transitions theory}

Unlike the perspectives outlined in the previous sections that have tended to focus on innovation processes at the level of individual energy technologies, research on sustainability transitions seeks to analyse how entire systems change over long time periods. Systems, as analysed in this field, are complex and large scale technical configurations which are essential to the functioning of modern societies. This includes energy supply systems, but also water supply and transport infrastructures. These systems are characterised by capital intensive and long lived infrastructure assets, they are resource intensive, and, because of their importance to economies and societies, they tend to be strongly influenced by policy and regulatory frameworks. Fundamentally, researchers in this field seek to understand the 
processes and dynamics of transitions, often with a view to informing policy on how to redirect such resource intensive systems towards sustainability.

In the sections below we introduce the origins of transitions research, how transitions have been conceptualised in different ways and we discuss some key applications and cases. This is followed by a view of the state-of-the-art of the field and future directions of research.

\subsubsection{Theoretical origins and key concepts}

Similar to the other innovation studies sub-disciplines discussed previously, sustainability transitions research emerged at the interface between a number of social science disciplines; evolutionary economics (Section 5.1), innovation systems (Section 5.2) and the sociology of science and technology. It represents a hybrid and emergent field, integrating a number of different but complimentary literatures.

The transitions approach was first proposed as a comprehensive theory of socio-technical change by the Dutch innovation scholars Arie Rip and René Kemp (Rip and Kemp, 1998). In their paper they draw on a wide range of theories of technological change in an effort to guide public policies relating to the environmental, emphasising the need for agents of change to understand the nature, dynamics and embeddedness of technological systems in society. They argue that policies that focus on innovation in single technology domain or individual entrepreneurs are inadequate. Instead policy needs to change the 'overall working system' (p.330). Furthermore, they argue that technology should be conceptualised, not in terms of discrete artefacts, but as part of complex systems; what they term 'configurations that work' (Rip \& Kemp p.338). Their key message is that a theory of innovation needs to incorporate change at multiple societal levels and they propose an analytical framework, which links: (1) individual entrepreneurs and localised processes; (2) sectoral and industrial structures; (3) and the wider 'social environment of technologies'. This work laid the theoretical foundations for the multi-level perspective on sustainability transitions (Section 5.3.2); a framework that has since become a widely referenced in the field and which we discuss further below.

Innovation as a process of changing socio-technical systems, the analysis of dynamics between different levels of a system, and a concern for the role of technologies and innovation in achieving broad sustainability goals are key distinctive features and contributions of sustainability transitions research. Below we expand upon these distinctive features: 
- Socio-technical systems: The unit of analysis in transitions research is not individual technologies, rather entire systems. How systems are framed and conceptualised is therefore crucial to an understanding of the transitions approach. The historian of technology Thomas Hughes in his book on the history of electricity systems "Networks of Power" (Hughes, 1983), coined the term socio-technical system. His view was that technical systems, like the electricity system, can only function if they are accompanied by supporting markets, laws, organisational frameworks and operational procedures, all of which require a degree of societal coordination and political consent.

- Sustainability and the direction of innovation: A second and very important feature of the transitions approach is that scholars in this field are typically more explicitly concerned with the overall direction of innovation and system change, specifically in terms of its implications for environmental sustainability. While innovation studies scholars from the evolutionary economics and innovation systems traditions see innovation as a positive attribute and an important driver of economic growth, there is less concern for the types of technologies that are undergoing innovation and their societal impacts. Unlike in ecological economics, where much of the literature is concerned with defining or reaching a version of a sustainable society, the normative aspect of transition studies tends to be based on politically defined goals, such as reaching decarbonisation targets, or achieving 'grand societal challenges' (e.g. UN's SDGs).

- A multi-level perspective on transitions: A third cornerstone of transitions research is the multi-level perspective (MLP); the core theoretical framework of transitions research. As discussed in the next section, the MLP conceptualises change in sociotechnical systems as a dynamic between three levels - niches, regimes and landscapes. Niches are local sites of innovation and experimentation, regimes are the established institutions and rules which provide stability and structure to systems, and landscapes are the wider social, political and natural environments in which systems are embedded. A transition is a shift from one regime to another which comes about as a result of the disruptive effects of innovations emerging from niches and landscape level changes, which destabilise regimes. 


\subsubsection{The Multi-level perspective}

The MLP as it has become the central analytical device in the field, around which debates and critiques tend to take place. Building on the initial theoretical insights of Rip and Kemp, another Dutch scholar, Frank Geels (2002), developed and refined a now popular framework which seeks to account for the complexity of systems and their dynamics. This was updated in a more recent paper and presented in Figure 9.16 (Geels and Schot, 2007).

Figure 9.16: A multi-level perspective on socio-technical transitions (Geels and Schot, 2007)

\section{Increasing structuration of activities in local practices}

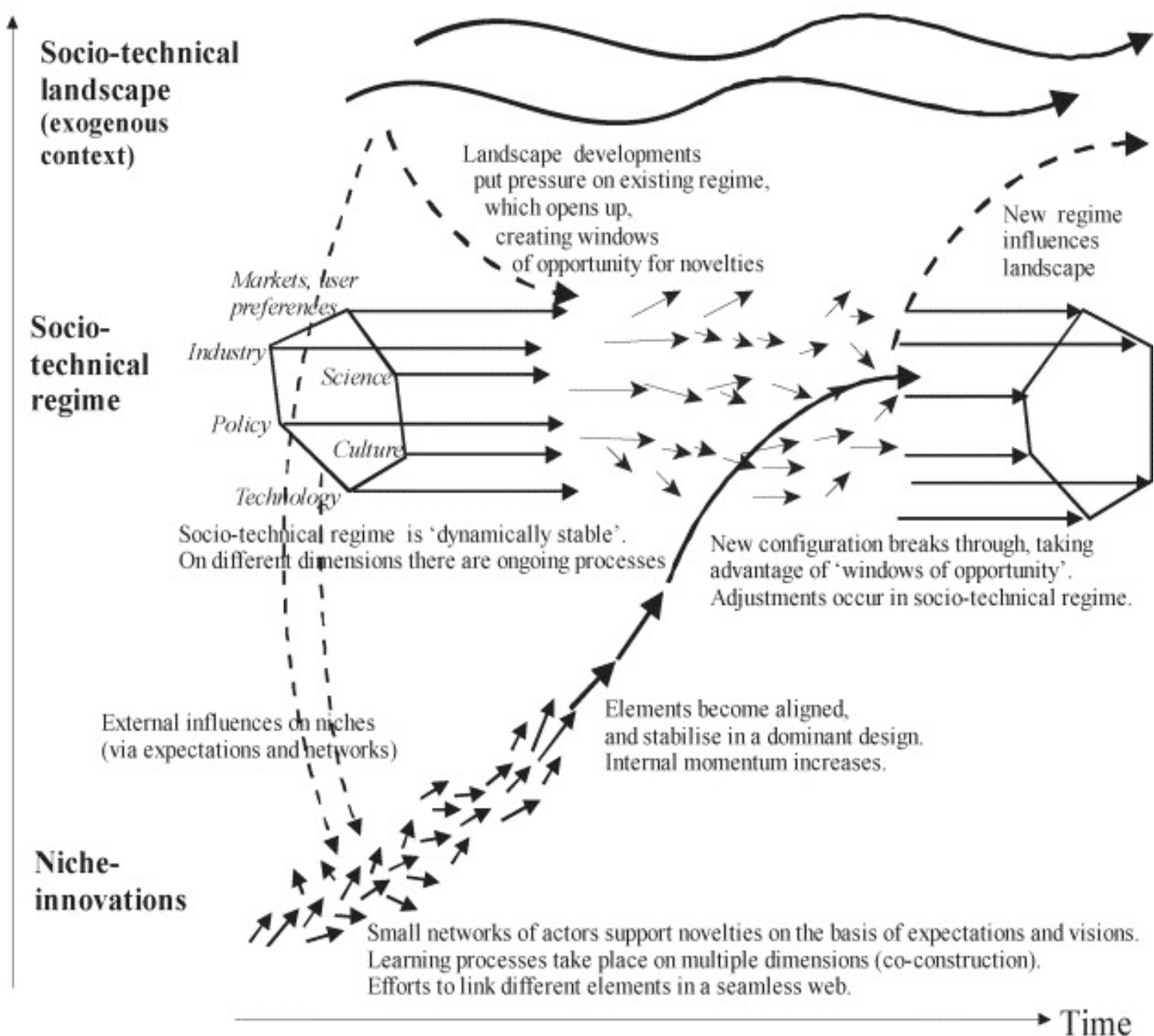

The MLP is essentially about understanding the nature and dynamics of technological system change. Systems are delineated into three conceptual levels as follows:

- Socio-technical regimes are the core of systems. They are composed of the connections between social and technical components which provide stability to 
systems, enabling them to function - their 'deep structures' (Geels, 2011). The composition of a regime is not fixed and depends on the particular system being analysed. In the case of electricity supply, for example, in order for the system to operate reliably, an industry structure with a set of technical codes and market rules is required, alongside a coherent regulatory and policy framework. But complex systems like electricity don't just operate according to such formal and tangible forms of coordination. Less formal aspects should also be considered, including professional cultures, taken for granted assumptions about systems, knowledge paradigms, cognitive frameworks, and common terminology and technical language shared amongst professionals in a sector.

- The landscape represents the socio-technical regime's environment or context, incorporating wider developments and trends such as demographics, climate change, wars, changing political ideologies and societal values. This is even more conceptually 'fuzzy' and difficult to delineate than the regime concept. However, it does serve the purpose of accounting for the influence of longer term and broader social and environmental trends, as well as potentially unexpected short term 'shocks', which aren't necessarily in the control of energy industry actors or even governments. If one takes a long term view on energy systems and how they have evolved over the $20^{\text {th }}$ century, it would be difficult to account for their growth and evolution without taking into account the first and second world wars for example. An example of a recent 'landscape shock' in the energy industry is the Japanese Fukushima nuclear power disaster in 2011 which has had profound impacts this has had on political and public support for nuclear power, most notably in Germany. These landscape developments can become branching points in transitions, i.e. 'key decision point $[\mathrm{s}]$ on a pathway at which choices made by actors, in response to internal or external pressures, determine whether and in what ways the pathway is followed' (Foxon et al., 2013 p.148). These constitute rare but critical moments that can dictate 'whether a particular pathway is followed, or a branch to another pathway may occur' (p.146).

- Finally, niches are where radical innovations first emerge and improve their performance in advance of being exposed to market competition or other technology selection processes. In essence they are protected spaces, enabling technologies to move thorough the innovation chain. Niches can exist within an organisation, for 
example as part of a company's R\&D programme, a government subsidy programme, or as part of a sub-market in which dominant technologies are not competing. In the energy and transport sector we can take the example of how battery electric vehicles were first adopted in niche markets such as on golf courses, delivering milk or at airports, before entering the mainstream through companies such as Tesla, Nissan and BMW.

As the figure above indicates, transitions involve the rapid growth of radical innovations which emerge out of localised niches, eventually becoming the 'dominant designs' around which new paradigms and regime structures develop. This pattern of technological change has resonances with work in management studies on 'disruptive innovation' where, despite inferior performance against characteristics valued by many customers, the initially inferior innovation can, over time, capture a significant portion of market share. As Christensen et al. (2015) explain, this is because incumbents tend to focus on meeting demand from the most profitable 'lead users', while new entrant firms are left with the less profitable market segments. This does however enable them to gain a foothold in the market and experiment. Because they are chasing profits at the high end, incumbents can lose perspective on the wider market trends and become detached from the main customer base. In some cases this leaves them vulnerable to competition from new entrants who have developed innovations with a wider range of technology attributes. They can thus eventually out-compete the incumbent.

This type of innovation narrative based around an outsider battling against an incumbent is certainty a popular and an attractive one. However, the history of previous technological transitions urges caution. While it may be the case in their early stages, key technologies around which energy regimes have been built, such as the internal combustion engine or the gas turbine (Smil, 2010a), were first developed by entrepreneurs that initially gained a foothold in market niches, rather than incumbent firms in established markets, transitions scholars have tended to overlook the role of incumbent firms in driving innovation. Much of the innovation that has transformed the way we use energy in society was about achieving marginal efficiency gains and took place through incremental innovation over many decades, with incumbent firms playing a key role (Rosenberg, 1976) (c.f. Section 2.1). For this reason, amongst others, the MLP has attracted criticism for over-simplifying transitions and conducting analyses in a way which conforms to an innovation narrative embedded in the 
conceptual scheme, rather than explaining the complexity and inherent unpredictability of socio-technical change (Bolton, Foxon and Hall, 2015).

In an attempt to address some of these concerns scholars have sought to open up thinking about the variety of potential transition pathways than can unfold. Drawing on examples of transitions in a range of sectors, Geels and Schot propose a typology of five pathways which are based on different dynamics between niche, regime and landscape levels (Geels and Schot, 2007):

- Reproduction - No external landscape pressure means the regime remains stable and reproduces itself

- Transformation - Landscape developments destabilize the regime but nicheinnovations are immature. There is no breakthrough for niche innovations but experiences from these are incorporated in the regime.

- Substitution - Landscape developments destabilize the regime when a nicheinnovation is mature. A window of opportunity emerges for the niche innovation to replace the regime.

- De-alignment/re-alignment - Landscape developments destabilize the regime when multiple niche-innovations are mature. These all take advantage of this window of opportunity, creating uncertainty around which will become dominant until alignment eventually occurs around a single one.

- Re-configuration - Landscape developments destabilize the regime when a nicheinnovation is mature, which is symbiotic to the regime. This enables incumbent actors to adopt this as an add-on, which may subsequently trigger other adjustments and change the regime's basic architecture.

There is no one model or pattern of a transition, but a framework like the MLP represents an intuitive and useful approach to conceptualising transitions can help us to structure our thinking in relation to such complex processes and help to guide policy in the area of energy innovation. In Box 9.6 we present two examples of how transitions thinking has been mobilised for this purpose. 


\section{Box 9.6 - The mobilisation of transitions thinking to inform energy policy}

\section{Example 1: The Dutch transitions programme}

In the early 2000s advocates of transitions thinking were successful in influencing Dutch energy policy as part of the Fourth Dutch National Environmental Policy Plan (NMP4). A number of scholars designed a policy programme called Transition Management (TM), which was partially based on the MLP. They advocated the identification of key promising sustainable energy technologies by government and the creation of niches wherein experimentation, learning, and network formation could take place, where they could become socially embedded. This approach, termed 'strategic niche management', was to be accompanied by regime destabilising measures, such as taxes and emissions standards. TM also involved the creation of new participatory 'arenas' where government, industry and civil society actors could come together to design new long term visions for socio-technical systems.

While this has been an interesting application of innovation theory as a policy guide, TM has come in for some criticism. Shove and Walker (2007), for example, characterise it as a technocratic project and raise concerns about the democratic legitimacy of such a process designed and coordinated by self-appointed 'transition managers' who aim to transform key aspects of society. Kern and Smith (2008) raise concerns that the approach has seen incumbent actors hijack the process and use it has a means of promoting their own economic interests and desired energy futures. This has inspired a recent strand within transition studies that examines the highly contested and political dimensions of transitions (Meadowcroft, 2011).

\section{Example 2: Developing transition pathways for the UK electricity system}

From 2008 to 2016 a group of UK academic researchers drew on transitions theory to develop long term pathways for the UK electricity system in order to explore feasible routes to achieving the UK government's 2050 target of reducing GHG emissions by at least $80 \%$ below 1990 levels. As we discussed in section 2 of the chapter, long term scenario and pathway analysis is key in understanding the likely mix of technologies required to deliver a low carbon future. Unlike most of the conventional energy system studies which are based on an engineering logic of cost optimality, the Transitions 
Pathways consortium set out to develop UK energy system pathways based on actor logics - how different actors view the energy challenge and work to influence change (Foxon, 2013). Drawing on the MLP and Geels and Schot's typology of pathways, three pathways were constructed each one based on market, government or civil society logics. An interesting aspect of the analysis was how the qualitative and actor-centric pathways were subsequently used as a basis to formally model the UK's energy transition (for an overview of how innovation studies and techno-economic approaches were combined see Chilvers et al. (2017)).

\subsection{Comparing and contrasting three perspectives on innovation and system change}

In discussing and comparing different perspectives on and approaches to the study of energy innovation it is important to understand their intellectual histories and theoretical origins, along with the aims and normative commitments of scholars in each field. No single conceptual framework can provide all the answers on the processes, drivers and barriers to energy innovation, so it is important to understand the strengths and limitations of each approach along with the areas of broad agreement and potential for synthesis. With this pluralist and interdisciplinary approach as our stance, in this section we compare and contrast the three theoretical perspectives on energy innovation and system change: evolutionary economics, innovation systems and socio-technical transitions.

Evolutionary economics teaches us that energy innovation is shaped by similar evolutionary mechanisms that shape the natural world (i.e. variation, selection and retention) and that such change is inherently dynamic, cumulative, systemic and uncertain. In particular, it is characterized by path dependency, positive feedbacks and co-evolution. Specifically, the approach offers some extremely important lessons about how incumbent fossil fuel technologies and business models have become locked-in and resistant to change, but also how such lock-in can be broken and positive feedbacks can be harnessed to help a lowcarbon transition gain momentum. Weaknesses of this approach include the difficulty of isolating positive feedbacks in such complex energy systems and drawing boundaries around the 'ecosystem' under investigation, in our case delineating the energy system. Furthermore, whilst co-evolutionary frameworks have been developed to forefront positive feedbacks, the approach lacks an analytical tool that offers a clear, operational framework of how energy 
innovation plays out as part of a historical narrative. It is therefore more limited to general insights into the complex dynamics of energy system change.

Innovation systems theory teaches us that innovation does not occur in a vacuum but is dependent on the presence of complex system of key actors, institutions, networks and infrastructures to perform functions that drive innovation. These systems can take many years to form and can go through periods of both formation, as well as degradation and reconfiguration. It has increasingly been adapted to offer longitudinal studies of how these support systems have evolved over time, offering a historical narrative of innovation as opposed to a snapshot in time. It is less well suited to highlighting the exogenous factors that shape innovation and possesses a narrow focus on how to support innovation, with little emphasis on wider political and societal factors which shape energy system change. This approach is best suited to case studies of how specific innovations (e.g. technology) have been supported within a specific geographical area (e.g. country). Its core aim is to help facilitate innovation, highlighting system failures attributed to the absence of key structural components or their lack of capacity in performing these functions, and identifying solutions to address these in order to accelerate innovation.

Finally, socio-technical transitions theory teaches us that energy system change does not simply involve the adoption of a new technology but the wholesale reconfiguration of social and technical components across various dimensions (e.g. science, markets, politics etc.). This system change is highly dependent on disrupting the status quo, primarily via the impact of disruptive innovations that emerge from outside the mainstream in niche markets and/or landscape developments, such as geo-political upheaval or environmental crises. This approach is helpful in uncovering the micro- and macro-developments that shape energy system transformations, especially the dynamics between incumbent and emergent innovations. It is a powerful means of building narratives of how and why system transitions unfold, with an emphasis on the timing and sequence of events. It also tends to be employed with a normative focus, often with the aim of realising a more sustainable society. However, the approach has some limitations, not least its over-emphasis on the role of niche markets and lack of consideration of the role incumbents can play in driving innovation. It has also been criticised for oversimplifying the extremely complex process of energy system change and can often be difficult to operationalise empirically to diagnose specific drivers and barriers to energy transitions. 


\section{Conclusions}

This chapter examines how and why energy innovation and sustainability transitions unfold. Following an overview of what constitutes energy innovation and transitions, we offer a comparison of what progress has been made in establishing a sustainable energy system versus what is required to avoid catastrophic climate change as part of the IEA's Sustainable Development Scenario. We find that despite impressive progress against some measures, such as installed capacity and cost of renewable energy, the pace of low-carbon energy technology innovation need to increase dramatically if we are to realise a sustainable energy system by 2040 . On the one hand this will require a significant increase in innovation funding, whilst on the other it demands that any existing or additional investment is spent as effectively as possible. It is also essential that the conditions are correct for these new technologies to enjoy wide-scale adoption from both business and consumers.

To help inform our understanding of what steps need to be taken to achieve these objectives this chapter offers an overview of three separate but related strand of theory: evolutionary economics, innovation systems and socio-technical transitions.

Evolutionary economics teaches us that energy innovation is shaped by similar evolutionary mechanisms responsible for the long-run changes we witness in the natural world (i.e. variation, selection and retention). Furthermore, such change is inherently dynamic, cumulative, systemic and uncertain, and it is characterized by path dependency, positive feedbacks and co-evolution.

Innovation systems theory teaches us that innovation does not occur in a vacuum but is dependent on the presence of complex system of key actors, institutions, networks and infrastructures to perform functions that drive innovation. These systems can take many years to form and can go through periods of both formation, as well as degradation and reconfiguration.

Finally, socio-technical transitions theory teaches us that energy system transformation does not simply involve the invention and subsequent adoption of new technologies but the wholesale reconfiguration of social and technical components across various dimensions (e.g. science, markets, politics etc.). At its heart system transitions rely on disruption of the status quo, which stems from either the effects of radical innovations that emerge from outside of the mainstream and/or landscape developments, such as geo-political upheaval or environmental crises. 
Whilst each approach offers different insights with regards to energy innovation and transitions, adopting different scales, boundaries and units of analysis, all three present effective tools in conceptualising energy innovation and system change from an alternative perspective to neo-classical economics. They are useful conceptual tools which inform our view of what a sustainable energy system might look like in the future and the types of actions we need to take to realise that vision.

\subsection{Exam or assignment questions}

We present below a number of questions relating to energy innovation and sustainability transitions to help students test their understanding of the topics covered in this chapter.

\subsubsection{Energy innovation}

For a given innovation (e.g. technology, business model, process etc.):

- What has been the history of the innovation's development? What and when was the first instance of its application? How has it evolved since then to the present day?

- Which factors have supported or hindered to the innovation's development? Specifically, how has government support shaped its progress?

- How has this innovation co-evolved with other innovations? For example, how has an innovative technology co-evolved with innovative business models?

\subsubsection{Energy system transitions}

For a given country or region:

- How has the energy system transformed during a given time period? What evidence can we draw upon to support these findings?

- Which factors have supported or constrained energy system change?

- How have positive feedback shaped energy system change? To what extent has sociotechnical lock-in served to reinforce the status quo?

- Which non-technological factors are having an important bearing on the energy system transitions? (E.g. government policy, informal institutions, environmental change etc.)

- How has the development of a single technology or suite of technologies shaped wider system change? Conversely, how has wider system change shaped the development of this technology/suite of technologies? 


\section{References}

A. Johnson and Jacobsson, S. (2000) 'Inducement and blocking mechanisms in the development of a new industry: the case of renewable energy technology in Sweden', in Coombes, R. et al. (eds) Technology and the Market. Demand, Users and Innovation. Cheltenham: Edward Elgar Publishig, pp. 89-111.

Aldrich, H. and Ruef, M. (2006) Organisations Evolving. 2nd edn. London: Sage Publications.

Andersen, E. S. and Lundvall, B.-A. (1997) 'National Innovation Systems and the Dynamics of the Division of Labor', in Edquist, C. (ed.) Systems of Innovation: Technologies, Institutions and Organizations. London: Routledge.

Andersson, J. et al. (2017) 'The critical role of informed political direction for advancing technology: The case of Swedish marine energy', Energy Policy. Elsevier, 101, pp. 52-64. doi: 10.1016/j.enpol.2016.11.032.

Arrow, K. (1962) 'The Economic Implications of Learning by Doing', American Economic Review, 29(3), pp. 155-173. doi: 10.2307/2295952.

Arthur, W. B. (1989) 'Competing technologies, increasing returns, and lock-in by historical events', The economic journal, 99(394), pp. 116-131. doi: 10.2307/2234208.

Arthur, W. B. (1990) 'Positive Feedbacks in the Economy', Scientific American, 262(November 1989), pp. 92-99.

Arthur, W. B. (1994) Increasing Returns and Path Dependence in the Economy. Michigan: University of Michigan Press.

Arthur, W. B. (1996) 'Increasing Returns and the New World of Business', Harvard Business Review. Harvard Business School Publication Corp., 74(4), pp. 100-109. Available at: http://search.ebscohost.com/login.aspx?direct=true\&db=buh\&AN=9607100436\&site=bsilive.

Bento, N. and Wilson, C. (2016) 'Measuring the duration of formative phases for energy technologies', Environmental Innovation and Societal Transitions. Elsevier B.V., 21, pp. 95112. doi: 10.1016/j.eist.2016.04.004.

Bergek, A. et al. (2008) 'Analyzing the functional dynamics of technological innovation systems: A scheme of analysis', Research Policy, 37(3), pp. 407-429. doi: 
10.1016/j.respol.2007.12.003.

Bergek, A. et al. (2015) 'Technological innovation systems in contexts: Conceptualizing contextual structures and interaction dynamics', Environmental Innovation and Societal Transitions. Elsevier B.V., 16, pp. 51-64. doi: 10.1016/j.eist.2015.07.003.

Bergek, A., Hekkert, M. and Jacobsson, S. (2008) 'Functions in Innovation Systems: A Framework for Analysing Energy System Dynamics and Identifying Goals for Systembuilding Activities by Entrepreneurs and Policymakers', in Foxon, T. J., Köhler, J., and Oughton, C. (eds) Innovation For A Low Carbon Economy: Economic, Institutional and Management Approaches. Edward Elgar, pp. 79-111.

Bergek, A. and Jacobsson, S. (2003) 'The emergence of growth industry: a comparative analysis of the German, Dutch and Swedish wind turbine industries', Change, Transformation and Development, (1), pp. 197-227. doi: 10.1007/978-3-7908-2720-0_12. Bergek, A., Jacobsson, S. and Sandén, B. A. (2008) “"Legitimation” and "development of positive externalities": Two key processes in the formation phase of technological innovation systems', Technology Analysis and Strategic Management, 20(5), pp. 575-592. doi: $10.1080 / 09537320802292768$.

van den Bergh, J. C. J. M. et al. (2006) 'Survival of the greenest: evolutionary economics and policies for energy innovation', Environmental Sciences, 3(1), pp. 57-71. doi: $10.1080 / 15693430500481295$.

Binz, C. et al. (2012) 'Conceptualizing leapfrogging with spatially coupled innovation systems: The case of onsite wastewater treatment in China', Technological Forecasting and Social Change, 79(1), pp. 155-171. doi: 10.1016/j.techfore.2011.08.016.

Binz, C. and Truffer, B. (2017) 'Global Innovation Systems-A conceptual framework for innovation dynamics in transnational contexts', Research Policy, 46(7), pp. 1284-1298. doi: 10.1016/j.respol.2017.05.012.

Bogenrieder, I. and Nooteboom, B. (2002) Social Structures for Learning. Rotterdam. Bolton, R. and Foxon, T. J. (2015) 'Infrastructure transformation as a socio-technical process - Implications for the governance of energy distribution networks in the UK', Technological Forecasting and Social Change, 90. doi: http://dx.doi.org/10.1016/j.techfore.2014.02.017. Bolton, R., Foxon, T. J. and Hall, S. (2015) 'Energy transitions and uncertainty: Creating low carbon investment opportunities in the UK electricity sector', Environment and Planning C: 
Government and Policy. doi: 10.1177/0263774X15619628.

Borup, M. et al. (2013) Indicators of energy innovation systems and their dynamics. DTU Management Engineering, Technical University of Denmark. Available at: http://orbit.dtu.dk/files/71114009/Indicators_of_energy_innovation.pdf.

Boutellier, R. and Heinzen, M. (2014) Growth Through Innovation - Managing the Technology-Driven Enterprise. Edited by R. Boutellier and M. Heinzen. New York: Spriner. doi: 10.1007/978-3-319-04016-5.

Brooks, H. (1995) 'What We Know and Do Not Know About Technology Transfer: Linking Knowledge to Action', in Marshaling technology for development. Washington, DC:

National Academy Press, pp. 83-96.

Bush, V. (1945) 'Science: the endless frontier', A report to the President on a Program for Postwar Scientific Research, (July), p. 252 p. doi: 10.2307/3625196.

Campbell, D. T. (1960) 'Blind variation and selective retention in creative thought as in other knowledge processes', Psychological Review, 67, pp. 380-400.

Carlsson, B. (2006) 'Internationalization of innovation systems: A survey of the literature', Research Policy, 35(1), pp. 56-67. doi: 10.1016/j.respol.2005.08.003.

Carlsson, B. and Jacobsson, S. (1997) 'In search of useful public policies- key lessons and issues for policy makers', in Technological Systems and Industrial Dynamics, pp. 299-315. doi: 10.1007/978-1-4615-6133-0.

Carlsson, B. and Stankiewicz, R. (1991) 'On the nature, function and composition of technological systems', Journal of Evolutionary Economics, 1(2), pp. 93-118. doi: 10.1007/BF01224915.

Chilvers, J. et al. (2017) 'Realising transition pathways for a more electric, low-carbon energy system in the United Kingdom: Challenges, insights and opportunities', Proceedings of the Institution of Mechanical Engineers, Part A: Journal of Power and Energy, 231(6), pp. 440-477. doi: 10.1177/0957650917695448.

Christensen, C. M., Raynon, M. E. and McDonald, R. (2015) 'What is Disruptive Innovation?', Harvard Business Review, (December), pp. 44-53. Available at: https://hbr.org/2015/12/what-is-disruptive-innovation.

Coenen, L. and Diaz Lopez, F. J. (2010) 'Comparing systems approaches to innovation and 
technological change for sustainable and competitive economies: An explorative study into conceptual commonalities, differences and complementarities', Journal of Cleaner Production. Elsevier Ltd, 18(12), pp. 1149-1160. doi: 10.1016/j.jclepro.2010.04.003.

Cooke, P., Gomez Uranga, M. and Etxebarria, G. (1997) 'Regional innovation systems: Institutional and organisational dimensions', Research Policy, 26(4-5), pp. 475-491. doi: 10.1016/S0048-7333(97)00025-5.

Cordes, C. (2006) 'Darwinism in economics: from analogy to continuity', Journal of Evolutionary Economics. Heidelberg, Netherlands, Heidelberg, 16(5), pp. 529-541. doi: 10.1007/s00191-006-0027-3.

Corsatea, T. D. (2014) 'Increasing synergies between institutions and technology developers: Lessons from marine energy', Energy Policy. Elsevier, 74, pp. 682-696. doi: 10.1016/j.enpol.2014.07.006.

Cowan, R. (1990) 'Nuclear Power Reactors: A Study in Technological Lock-in', The Journal of Economic History. Cambridge University Press on behalf of the Economic History Association, 50(3), pp. 541-567. Available at: http://www.jstor.org/stable/2122817. Darmani, A. et al. (2014) 'What drives the development of renewable energy technologies? Toward a typology for the systemic drivers', Renewable and Sustainable Energy Reviews. Elsevier, 38(January), pp. 834-847. doi: 10.1016/j.rser.2014.07.023.

David, P. a. (1985) 'Clio and the Economics of QWERTY.', American Economic Review, 75(2), pp. 332-337. doi: Article.

David, P. A. and Bunn, J. A. (1988) 'The economics of gateway technologies and network evolution: Lessons from electricity supply history', Information Economics and Policy, 3(2), pp. 165-202. doi: 10.1016/0167-6245(88)90024-8.

Dawkins, R. (1976) The Selfish Gene. New York: Oxford University Press.

Deloitte (2017) The arc of innovation in the oil and gas industry: Using US patent databases to track trends. Available at: https://www2.deloitte.com/us/en/pages/energy-andresources/articles/tracking-innovation-in-oil-and-gas-patents.html (Accessed: 8 January 2017).

Dewald, U. and Truffer, B. (2011) 'Market Formation in Technological Innovation Systems-Diffusion of Photovoltaic Applications in Germany', Industry \& Innovation, 18(3), pp. 285-300. doi: 10.1080/13662716.2011.561028. 
Economides, N. (2006) 'Competition policy in network industries: an introduction', in Jansen, D. W. (ed.) The New Economy and Beyond Past, Present and Future. Edward Elgar.

Edquist, C. (2001) 'The Systems of Innovation Approach and Innovation Policy: An account of the state of the art', DRUID Conference, Aalborg, pp. 12-15.

Edquist, C. (2006) 'Systems of Innovation: Perspectives and Challenges', in Fagerberg, J. (ed.) The Oxford Handbook of Innovation. Oxford University Press: Oxford, pp. 181-208. Available at: https://charlesedquist.files.wordpress.com/2015/04/systems-of-innovationperspectives-and-challenges-oxford-handbooks.pdf.

Edsand, H. E. (2016) 'Technological Innovation Systems and the wider context: A framework for developing countries', UNU-MERIT working papers, (17), p. 38. Available at: http://www.merit.unu.edu/publications/working-papers/abstract/?id=5999.

Fagerberg, J. (2003) Innovation: A Guide to the Literature. doi:

10.1093/oxfordhb/9780199286805.003.0001.

Fouquet, R. (2010) 'The slow search for solutions: Lessons from historical energy transitions by sector and service', Energy Policy. Elsevier, 38(11), pp. 6586-6596. doi:

10.1016/j.enpol.2010.06.029.

Fouquet, R. (2016) 'Historical energy transitions: Speed, prices and system transformation', Energy Research and Social Science. Elsevier Ltd, 22, pp. 7-12. doi:

10.1016/j.erss.2016.08.014.

Foxon, T. J. (2003) Inducing innovation for a low-carbon future: drivers, barriers and policies. London: Centre for Energy Policy \& Technology, Imperial College, London.

Foxon, T. J. (2011) 'A coevolutionary framework for analysing a transition to a sustainable low carbon economy', Ecological Economics, 70(12), pp. 2258-2267. Available at: http://www.sciencedirect.com/science/article/pii/S0921800911002898.

Foxon, T. J. et al. (2013) 'Branching points for transition pathways: assessing responses of actors to challenges on pathways to a low carbon future', Energy Policy. Elsevier, 52, pp. 146-158. doi: 10.1016/j.enpol.2012.04.030.

Foxon, T. J. (2013) 'Transition pathways for a UK low carbon electricity future', Energy Policy, 52(0), pp. 10-24. doi: http://dx.doi.org/10.1016/j.enpol.2012.04.001.

Freeman, C. (1987) Technology Policy and Economic Performance: Lessons from Japan. 
Continuum International Publishing.

Freeman, C. and Perez, C. (1988) 'Structural crises of adjustment, business cycles and investment behaviour', in Dosi, G. et al. (eds) Technical Change and Economic Theory. Pisa, Italy: Sant'Anna School of Advanced Studies, pp. 38-66. doi: 10.2307/2234048.

Gallagher, K. S. (2006) 'Limits to leapfrogging in energy technologies? Evidence from the Chinese automobile industry', Energy Policy, 34(4), pp. 383-394. doi:

10.1016/j.enpol.2004.06.005.

Gallagher, K. S. et al. (2012) 'The Energy Technology Innovation System', Annual Review of Environment and Resources, 37(1), pp. 137-162. doi: 10.1146/annurev-environ-060311133915.

GE (2016) BREAKING THE POWER PLANT EFFICIENCY RECORD. Available at: https://www.gepower.com/about/insights/articles/2016/04/power-plant-efficiency-record (Accessed: 1 February 2018).

Geels, F. and Schot, J. (2007) 'Typology of sociotechnical transition pathways', Research Policy, pp. 399-417 SRC-GoogleScholar FG-0. Available at: https://www.sciencedirect.com/science/article/pii/S0048733307000248.

Geels, F. W. (2002) 'Technological transitions as evolutionary reconfiguration processes: a multi-level perspective and a case-study', Research policy.

Geels, F. W. (2011) 'The multi-level perspective on sustainability transitions: Responses to seven criticisms', Environmental Innovation and Societal Transitions, 1(1), pp. 24-40. doi: http://dx.doi.org/10.1016/j.eist.2011.02.002.

Global CCS Institute (2019) Global Status Report. Available at: https://www.globalccsinstitute.com/resources/global-status-report/ (Accessed: 10 April 2019).

Gosens, J. and Lu, Y. (2013) 'From lagging to leading? Technological innovation systems in emerging economies and the case of Chinese wind power', Energy Policy. Elsevier, 60, pp. 234-250. doi: 10.1016/j.enpol.2013.05.027.

Griliches, Z. (1957) 'Hybrid Corn: An Exploration in the Economics of Technological Change', Econometrica, 25(4), p. 501. doi: 10.2307/1905380.

Gross, R. et al. (2018) 'How long does innovation and commercialisation in the energy 
sectors take? Historical case studies of the timescale from invention to widespread commercialisation in energy supply and end use technology, ', Energy Policy.

Grubler, A. (2014) 'The French pressurised water reactor programme', in Wilson, C. and Grübler, A. (eds) Energy Technology Innovation: Learning from Historical Successes and Failures. Cambridge: Cambridge University Press, pp. 146-162. doi:

10.1017/CBO9781139150880.015.

Grübler, A. (1998) Technology and Global Change. Camrbidge: Cambridge University Press. Grübler, A. et al. (2012) 'Chapter 24 - Policies for the Energy Technology Innovation System (ETIS)', in Global Energy Assessment - Toward a Sustainable Future. Cambridge University Press, Cambridge, UK and New York, NY, USA and the International Institute for Applied Systems Analysis, Laxenburg, Austria, pp. 1665-1744. Available at: http://www.iiasa.ac.at/web/home/research/Flagship-Projects/Global-EnergyAssessment/GEA_Chapter24_ETIS_hires.pdf.

Grubler, A., Wilson, C. and Nemet, G. (2016) 'Apples, oranges, and consistent comparisons of the temporal dynamics of energy transitions', Energy Research and Social Science. Elsevier Ltd, 22, pp. 18-25. doi: 10.1016/j.erss.2016.08.015.

Hannon, M. (2012) Co-evolution of innovative business models and sustainability transitions: The case of the Energy Service Company (ESCo) model and the UK energy system, School of Earth and Environment. University of Leeds. Available at: http://etheses.whiterose.ac.uk/3660/.

Hannon, M. J., Van Diemen, R. and Skea, J. (2017) Examining the effectiveness of support for UK wave energy innovation since 2000. Lost at sea of a new wave of innovation? Glasgow. doi: http://dx.doi.org/10.17868/62210.

Hannon, M. J., Van Diemen, R. and Skea, J. (2018) 'Examining the effectiveness of support for UK wave energy innovation since 2000. Lost at sea of a new wave of innovation?', in International Sustainability Transitions 2018. Manchester. doi: http://dx.doi.org/10.17868/62210.

Hannon, M. J., Foxon, T. J. and Gale, W. F. (2013) 'The co-evolutionary relationship between energy service companies and the UK energy system: Implications for a low-carbon transition', Energy Policy, 61. doi: 10.1016/j.enpol.2013.06.009.

Hawkey, D. J. C. (2012) 'District heating in the UK: A Technological Innovation Systems 
analysis', Environmental Innovation and Societal Transitions. Elsevier B.V., 5, pp. 19-32. doi: 10.1016/j.eist.2012.10.005.

Hekkert, M. P. et al. (2007) 'Functions of innovation systems: A new approach for analysing technological change', Technological Forecasting and Social Change, 74(4), pp. 413-432. Available at: http://www.sciencedirect.com/science/article/pii/S0040162506000564.

Hekkert, M. P. et al. (2011) Technological Innovation System Analysis: a manual for analysts, Utrecht University. Utrecht. Available at: http://www.innovation-system.net/wpcontent/uploads/2013/03/UU_02rapport_Technological_Innovation_System_Analysis.pdf.

Hekkert, M. P., Harmsen, R. and de Jong, A. (2007) 'Explaining the rapid diffusion of Dutch cogeneration by innovation system functioning', Energy Policy, 35(9), pp. 4677-4687. doi: 10.1016/j.enpol.2007.02.018.

Hekkert, M. P. and Negro, S. O. (2009) 'Functions of innovation systems as a framework to understand sustainable technological change: Empirical evidence for earlier claims', Technological Forecasting and Social Change. Elsevier Inc., 76(4), pp. 584-594. doi: 10.1016/j.techfore.2008.04.013.

Heylighen, F. (1992) 'Principles of Systems and Cybernetics: an evolutionary perspective', in Trappl, R. (ed.) Cybernetics and Systems . Singapore: World Science, pp. 3-10.

Hillman, K. et al. (2011) 'Fostering sustainable technologies: a framework for analysing the governance of innovation systems', Science and Public Policy, 38(5), pp. 403-415. doi: $10.3152 / 030234211 X 12960315267499$.

Hillman, K. M. et al. (2008) 'Cumulative causation in biofuels development: a critical comparison of the Netherlands and Sweden', Technology Analysis \& Strategic Management, 20(5), pp. 593-612. doi: 10.1080/09537320802292826.

Hodgson, G. M. (2002) 'Darwinism in economics: from analogy to ontology', Journal of Evolutionary Economics. Springer Berlin / Heidelberg, 12(3), pp. 259-281. doi: 10.1007/s00191-002-0118-8.

Hodgson, G. M. (2003) 'The Mystery of the Routine: The Darwinian Destiny of An Evolutionary Theory of Economic Change', Revue Economique, 54(2), pp. 355-384. doi: $10.2307 / 3503007$.

Hodgson, G. M. (2005) 'Generalizing Darwinism to Social Evolution: Some Early Attempts', Journal of Economic Issues. Association for Evolutionary Economics, 39(4), pp. 899-914. 
Available at: http://www.jstor.org/stable/4228199.

Hu, R. (2017) The Chinese innovation system for wind energy: structure, functions and performance. Imperial College London. Available at:

https://spiral.imperial.ac.uk/bitstream/10044/1/52434/1/Hu-R-2017-PhD-Thesis.pdf.

Hu, R., Skea, J. and Hannon, M. J. (2017) 'Measuring the energy innovation process: an indicator framework and a case study of wind energy in China', Technological Forecasting \& Social Change, in press. Available at:

https://www.sciencedirect.com/science/article/pii/S0040162516302992.

Hughes, T. P. (1983) Networks of Power, Electrification in Western Society, 1880-1930. Baltimore: Johns Hopkins University Press.

IEA (2011) Guide to Reporting Energy RD\&D Budget Statistics. Paris. Available at: http://www.iea.org/stats/RDD Manual.pdf.

IEA (2015) Energy Technology Perspectives 2015, International Energy Agency. doi: 10.1787/energy_tech-2015-en.

IEA (2017) International Energy Agency: Renewables Information. OECD Renewables Supply and Consumption 1990-2015. Available at:

http://stats.ukdataservice.ac.uk/index.aspx?r=349707\&DataSetCode=IEA_COAL_BA (Accessed: 1 February 2018).

IEA (2018a) IEA Energy RD\&D Data. Paris. Available at: http://wds.iea.org/wds/ReportFolders/ReportFolders.aspx.

IEA (2018b) Key World Energy Statistics 2018. doi: 10.1016/j.gie.2015.03.199.

IEA (2018c) Market Report Series: Energy Efficiency 2O18. Available at: https://webstore.iea.org/market-report-series-energy-efficiency-2018.

IEA (2018d) 'World Energy Outlook 2018'. Available at: https://www.iea.org/weo/. IEA (2019a) Fuel prices. Available at: https://www.iea.org/statistics/kwes/prices/ (Accessed: 10 April 2019).

IEA (2019b) Global Energy \& CO2 Status Report: The latest trends in energy and emissions in 2018. Available at: https://www.iea.org/geco/emissions/ (Accessed: 1 April 2019).

IEA (2019c) Glossary. Available at: https://www.iea.org/about/glossary/t/ (Accessed: 3 April 2019). 
IEA (2019d) Monthly oil statistics. Available at:

https://www.iea.org/media/statistics/surveys/prices/mps.xls.

IEA (2019e) Scenarios in WEO 2018. Available at: https://www.iea.org/weo/weomodel/ (Accessed: 3 April 2019).

IEA (2019f) World Energy Outlook 2018: Scenarios. Available at:

https://www.iea.org/weo2018/scenarios/ (Accessed: 3 April 2019).

IPCC (2018) Summary for Policymakers - Global Warming of $1.5^{\circ} \mathrm{C}$. Generva. Available at: http://www.ipcc.ch/report/sr15/.

IRENA (2018a) Renewable Electricity Capacity and Generation Statistics query tool. Available at:

$\mathrm{http}: / /$ resourceirena.irena.org/gateway/dashboard/index.html?topic=4\&subTopic=16\# (Accessed: 3 April 2019).

IRENA (2018b) Renewable Power Generation Costs in 2017, International Renewable Energy Agency. doi: 10.1007/SpringerReference_7300.

IRENA (2019) Patents Evolution. Available at:

http://resourceirena.irena.org/gateway/dashboard/?topic=1019\&subTopic=1058 (Accessed: 3 February 2018).

Jacobsson, S. and Bergek, A. (2011) 'Innovation system analyses and sustainability transitions: Contributions and suggestions for research', Environmental Innovation and Societal Transitions, 1(1), pp. 41-57. doi: http://dx.doi.org/10.1016/j.eist.2011.04.006. Jacobsson, S. and Karltorp, K. (2013) 'Mechanisms blocking the dynamics of the European offshore wind energy innovation system - Challenges for policy intervention', Energy Policy, 63, pp. 1182-1195. doi: 10.1016/j.enpol.2013.08.077.

Jacobsson, S., Sandén, B. and Bangens, L. (2004) 'Transforming the energy system - the evolution of the German technological system for solar cells', Technology Analysis \& Strategic Management, 16(1), pp. 3-30. doi: 10.1080/0953732032000199061.

Johnson, A. and Jacobsson, S. (2001) 'Inducement and blocking mechanisims in the development of a new industry: the case of renewable energy technology in Sweden', in Technology and the Market: Demand, Users and Innovation, pp. 89-113.

Kallis, G. (2007) 'When is it coevolution?', Ecological Economics, 62(1), pp. 1-6. doi: 
10.1016/j.ecolecon.2006.12.016.

Kallis, G. and Norgaard, R. B. (2010) 'Coevolutionary ecological economics', Ecological Economics, 69(4), pp. 690-699. doi: http://dx.doi.org/10.1016/j.ecolecon.2009.09.017.

Kamp, L. M., Smits, R. E. H. M. and Andriesse, C. D. (2004) 'Notions on learning applied to wind turbine development in the Netherlands and Denmark', Energy Policy, 32(14), pp. 1625-1637. doi: 10.1016/S0301-4215(03)00134-4.

Kander, A., Malanima, P. and Warde, P. (2013) Power to the People: Energy in Europe Overthe Last Five Centuries. Princeton, NJ: Princeton University Press.

Karltorp, K., Guo, S. and Sandén, B. A. (2017) 'Handling financial resource mobilisation in technological innovation systems - The case of chinese wind power', Journal of Cleaner Production, 142(January 2012), pp. 3872-3882. doi: 10.1016/j.jclepro.2016.10.075.

Kemp, R., Schot, J. and Hoogma, R. (1998) 'Regime shifts to sustainability through processes of niche formation: The approach of strategic niche management', Technology Analysis \& Strategic Management, 10(2), pp. 175-195. doi: 10.1080/09537329808524310.

Kern, F. (2015) 'Engaging with the politics, agency and structures in the technological innovation systems approach', Environmental Innovation and Societal Transitions, 16, pp. 67-69. doi: 10.1016/j.eist.2015.07.001.

Kern, F. and Smith, A. (2008) 'Restructuring energy systems for sustainability? Energy transition policy in the Netherlands', Energy Policy, 36(11), pp. 4093-4103. doi: 10.1016/j.enpol.2008.06.018.

Klagge, B., Liu, Z. and Campos Silva, P. (2012) 'Constructing China's wind energy innovation system', Energy Policy, 50, pp. 370-382. doi: 10.1016/j.enpol.2012.07.033. Kline, S. J. and Rosenberg, N. (1986) 'An Overview of Innovation', in Landau, R. and Rosenberg, N. (eds) The Positive Sum Strategy: Harnessing Technology for Economic Growth. Washington D.C.: National Academy Press,.

Klitkou, A. et al. (2015) 'The role of lock-in mechanisms in transition processes: The case of energy for road transport', Environmental Innovation and Societal Transitions. Elsevier B.V., 16, pp. 22-37. doi: 10.1016/j.eist.2015.07.005.

Klitkou, M., Iversen, E. and Borup, A. (2012) Energy Innovation Systems: Indicator Report 2012. Available at: http://www.eis- 
all.dk/ /media/Sites/EIS_Energy_Innovation_Systems/english/about eis/Publications/Energy Inn Syst Indicator rep 2012 Final.ashx.

Korotayev, A., Zinkina, J. and Bogevolnov, J. (2011) 'Kondratieff waves in global invention activity (1900-2008)', Technological Forecasting and Social Change, 78(7), pp. 1280-1284. doi: 10.1016/j.techfore.2011.02.011.

Lundvall, B.-Å. (1992) National Systems of Innovation: Towards a Theory of Innovation and Interactive Learning, National systems of innovation Towards a theory of innovation and interactive learning. doi: 10.1080/08109029308629360.

Lundvall, B.-Å. and Vinding, A. L. (2004) 'Product Innovation and Economic Theory User-Producer Interaction in the Learning Economy', in, pp. 101-128. doi: 10.1016/S07371071(04)08005-9.

Lundvall, B. (2007) 'National Innovation Systems-Analytical Concept and Development Tool', Industry \& Innovation, 14(1), pp. 95-119. doi: 10.1080/13662710601130863.

Malerba, F. (2002) 'Sectoral systems of innovation and production \&’, 31, pp. 247-264.

Markard, J. (2018) 'The life cycle of technological innovation systems', Technological Forecasting and Social Change. doi: https://doi.org/10.1016/j.techfore.2018.07.045.

Markard, J., Hekkert, M. and Jacobsson, S. (2015) 'The technological innovation systems framework: Response to six criticisms', Environmental Innovation and Societal Transitions. Elsevier B.V., 16, pp. 76-86. doi: 10.1016/j.eist.2015.07.006.

Markard, J. and Truffer, B. (2008) 'Actor-oriented analysis of innovation systems: exploring micro-meso level linkages in the case of stationary fuel cells', Technology Analysis \& Strategic Management, 20(4), pp. 443-464. doi: 10.1080/09537320802141429.

Mayr, E. (1991) One long argument: Charles Darwin and the Genesis of modern evolutionary theory. Cambridge, Massachusetts: Harvard University Press.

Meadowcroft, J. (2011) 'Engaging with the politics of sustainability transitions', Environmental Innovation and Societal Transitions, 1(1), pp. 70-75. doi: 10.1016/j.eist.2011.02.003.

Meyer, D. et al. (2014) 'Brazilian Ethanol: Unpacking a Success Story of Energy Technology Innovation', in Wilson, C. and Grübler, A. (eds) Energy Technology Innovation Learning from Historical Successes and Failures. Cambridge: Cambridge University Press, pp. 275- 
291.

Miremadi, I., Saboohi, Y. and Jacobsson, S. (2018a) 'Assessing the performance of energy innovation systems: Towards an established set of indicators', Energy Research and Social Science. Elsevier, 40(January), pp. 159-176. doi: 10.1016/j.erss.2018.01.002.

Miremadi, I., Saboohi, Y. and Jacobsson, S. (2018b) 'Assessing the performance of energy innovation systems: Towards an established set of indicators', Energy Research \& Social Science. Elsevier, 40(August 2017), pp. 159-176. doi: 10.1016/j.erss.2018.01.002.

Mission Innovation (2019) Overview.

Mokyr, J. (1992) 'The Middle Ages', in The Lever of Riches: Technological Creativity and Economic Progress, pp. 33-56. doi: 10.1093/acprof:oso/9780195074772.001.0001.

Mukoyama, T. (2006) 'Rosenberg's “learning by using” and technology diffusion', Journal of Economic Behavior \& Organization, 61(1), pp. 123-144. doi: 10.1016/j.jebo.2004.10.009.

Mulder, K. F. (2007) 'Innovation for sustainable development: From environmental design to transition management', Sustainability Science, 2(2), pp. 253-263. doi: 10.1007/s11625-0070036-7.

Murmann, J. P. (2003) Knowledge and Competitive Advantage - The Coevolution of Firms, Technology, and National Institutions . Cambridge: Cambridge University Press.

Murmann, J. P. (2013) 'The Coevolution of Industries and Important Features of Their Environments', Organization Science, 24(58-78). doi: 10.1287/orsc.1110.0718.

Negro, S. O. and Hekkert, M. P. (2008) 'Explaining the success of emerging technologies by innovation system functioning: the case of biomass digestion in Germany', Technology Analysis \& Strategic Management, 20(4), pp. 465-482. doi: 10.1080/09537320802141437.

Nelson, R. R. (1993) 'National innovation systems: a comparative analysis', University of Illinois at Urbana-Champaign's Academy for Entrepreneurial Leadership Historical Research Reference in Entrepreneurship.

Nelson, R. R. (1994) 'The Co-evolution of Technology, Industrial Structure, and Supporting Institutions', Industrial and Corporate Change, 3(1), pp. 47-63. doi: 10.1093/icc/3.1.47.

Nelson, R. R. and Winter, S. G. (1982) An Evolutionary Theory of Economic Change. Cambridge, MA: Hardvard University Press.

Nemet, G. F. (2014) 'Solar Water Heater Innovation in the United States, China, and 
Europe', in Wilson, C. and Grübler, A. (eds) Energy Technology Innovation: Learning from Historical Successes and Failures. Cambridge: Cambridge University Press, pp. 105-117.

Norgaard, R. (1994) Development Betrayed: The End of Progress and a Coevolutionary Revisioning of the Future. London \& New York: Routledge.

North, D. C. (1990) 'Institutions, institutional change, and economic performance', Economic Perspective, 5(1), pp. 97-112.

Patana, A. S. et al. (2013) 'Inducement and blocking mechanisms in the Finnish life sciences innovation system', Foresight, 15(6), pp. 428-445. doi: 10.1108/FS-10-2012-0081.

Pierson, P. (2000) 'Increasing Returns, Path Dependence, and the Study of Politics', American Political Science Review, 94(02), pp. 251-267. doi: 10.2307/2586011.

Quitzow, R. (2015) 'Dynamics of a policy-driven market: The co-evolution of technological innovation systems for solar photovoltaics in China and Germany', Environmental Innovation and Societal Transitions. Elsevier B.V., 17, pp. 126-148. doi: 10.1016/j.eist.2014.12.002.

Reichardt, K. et al. (2016) 'Analyzing interdependencies between policy mixes and technological innovation systems: The case of offshore wind in Germany', Technological Forecasting and Social Change. Elsevier Inc., 106, pp. 11-21. doi:

10.1016/j.techfore.2016.01.029.

Rip, A. and Kemp, R. (1998) 'Technological change', Human Choice and Climate Change, 2(Vol. 2: Resources and Technology), pp. 327-399. doi: 10.1007/BF02887432.

Robb, D. (2010) CCGT: Breaking the 60 per cent efficiency barrier. Available at: http://www.powerengineeringint.com/articles/print/volume-18/issue-3/features/ccgtbreaking-the-60-per-cent-efficiency-barrier.html.

Rogers, E. (1962) Diffusion of Innovations. 1st edn. New York: The Free Press.

Rosenberg, N. (1976) Perspectives on Technology. Cambridge: Cambridge University Press. Available at: https://doi.org/10.1017/CBO9780511561313.

Rosenberg, N. (1982) Inside the Black Box: Technology and Economics. Edited by Cambridge and U. Press. Cambridge.

Ru, P. et al. (2012) 'Behind the development of technology: The transition of innovation modes in China's wind turbine manufacturing industry', Energy Policy, 43, pp. 58-69. doi: 
10.1016/j.enpol.2011.12.025.

Schmookler, J. (1966) Invention and Economic Growth. Cambridge MA: Harvard University Press.

Schumpeter, J. (1934) 'The theory of economic development', Joseph Alois Schumpeter, pp. 61-116.

Schumpeter, J. A. (1942) Capitalism, Socialism and Democracy. New York: Harper and Row.

Sewell, W. (1996) 'Three temporalities: towards an eventful sociology', in McDonald, T. (ed.) The Historic Truth in the Human Sciences. Ann Arbor, MI: University of Michigan Press, pp. 245-280.

Shove, E. and Walker, G. (2007) 'CAUTION! Transitions ahead: Politics, practice, and sustainable transition management', Environment and Planning A, pp. 763-770. doi: 10.1068/a39310.

Simon, H. A. (1956) 'Rational choice and the structure of the environment', Psychological Review, 63(2), pp. 129-138. doi: 10.1037/h0042769.

Simon, H. A. (1959) 'Theories of decision making in economics and behavioral science', The American Economic Review, 49(3), pp. 253-283.

Smil, V. (2010a) Energy Transitions: History, Requirements, Prospects. Santa Barbara: Praeger/ABC CLIO.

Smil, V. (2010b) Energy Transitions: National and Global Perspectives. SantaBarbara, CA: Praeger.

Smith, A. and Raven, R. (2012) 'What is protective space? Reconsidering niches in transitions to sustainability', Research Policy, 41(6), pp. 1025-1036. doi:

10.1016/j.respol.2011.12.012.

Smith, K. (2000) 'Innovation as a Systemic Phenomenon: Rethinking the Role of Policy', Enterprise and Innovation Management Studies, 1(1), pp. 73-102. doi:

$10.1080 / 146324400363536$.

Smits, R. and Kuhlmann, S. (2004) 'The rise of systemic instruments in innovation policy', International Journal of Foresight and Innovation Policy, 1(1/2), p. 4. doi: 10.1504/IJFIP.2004.004621. 
Spataru, C. (2017) Whole Energy System Dynamics: Theory, modelling and policy. London: Routledge.

Suurs, R. A. A. (2009) Motors of sustainable innovation. Towards a theory on the dynamics of technological innovation systems. Utrecht. Available at:

https://dspace.library.uu.nl/bitstream/handle/1874/33346/suurs.pdf?sequence=2.

Suurs, R. A. A. and Hekkert, M. P. (2009) 'Cumulative causation in the formation of a technological innovation system: The case of biofuels in the Netherlands', Technological Forecasting and Social Change, 76(8), pp. 1003-1020. doi: 10.1016/j.techfore.2009.03.002.

Taylor, M., Ralon, P. and Ilas, A. (2016) The power to change: solar and wind cost reduction potential to 2025. Available at:

http://www.irena.org/DocumentDownloads/Publications/IRENA_Power_to_Change_2016.pd f.

Thompson, J. N. (1994) The Coevolutionary Process. Chicago: University of Chicago Press.

Tukker, A. (2005) 'Leapfrogging into the future: developing for sustainability', International Journal of Innovation and Sustainable Development, 1(1/2), p. 65. doi:

10.1504/IJISD.2005.008087.

UKRN (2015) 'Innovation in regulated infrastructure sectors', in. London.

UNFCCC (2016) The Paris Agreement. Available at:

http://unfccc.int/paris_agreement/items/9485.php (Accessed: 19 December 2016).

Unruh, G. (2000) 'Understanding carbon lock-in’, Energy policy, 28(March), pp. 817-830. doi: 10.1016/S0301-4215(00)00070-7.

Unruh, G. C. (2002) ‘Escaping carbon lock-in’, Energy Policy, 30(4), pp. 317-325.

Unruh, G. C. and Carrillo-Hermosilla, J. (2006) 'Globalizing carbon lock-in', Energy Policy, 34(10), pp. 1185-1197. doi: 10.1016/j.enpol.2004.10.013.

USEPA (2018) Light-Duty Automotive Technology, Carbon Dioxide Emissions, and Fuel Economy Trends: 1975 Through 2017. Available at: https://www.epa.gov/sites/production/files/2018-01/documents/420s18001.pdf. Vantoch-Wood, A. R. (2012) Quantifying Methods for an Innovation Systems Analysis of the UK Wave Energy Sector. University of Exeter. Available at: https://ore.exeter.ac.uk/repository/bitstream/handle/10871/11122/Vantoch- 
WoodA.pdf?sequence=1.

Weber, K. M. and Truffer, B. (2017) 'Moving innovation systems research to the next level: Towards an integrative agenda', Oxford Review of Economic Policy, 33(1), pp. 101-121. doi: 10.1093/oxrep/grx002.

Wieczorek, A. J. and Hekkert, M. P. (2012) 'Systemic instruments for systemic innovation problems: A framework for policy makers and innovation scholars', Science and Public Policy, 39(1), pp. 74-87. doi: 10.1093/scipol/scr008.

Wilson, C. (2014) 'Input, Output, and Outcome Metrics for Assessing Energy Technology Innovation', in Energy Technology Innovation Learning from Historical Successes and Failures. Cambridge: Cambridge University Press, pp. 75-88.

Wilson, C. and Grübler, A. (2014) 'The Energy Technology Innovation System', in Energy Technology Innovation: Learning from Historical Successes and Failures. New York:

Cambridge University Press, pp. 11-29. doi: 10.1007/s13398-014-0173-7.2.

Wilson, C. and Tisdell, C. (2001) 'Why farmers continue to use pesticides despite environmental, health and sustainability costs', Ecological Economics, 39(3), pp. 449-462. doi: 10.1016/S0921-8009(01)00238-5.

Woolthuis, R. K., Lankhuizen, M. and Gilsing, V. (2005) 'A system failure framework for innovation policy design', Technovation, 25(6), pp. 609-619. doi:

10.1016/j.technovation.2003.11.002.

Zhao, Z. yu et al. (2012) 'Comparative assessment of performance of foreign and local wind turbine manufacturers in China', Renewable Energy, 39(1), pp. 424-432. doi:

10.1016/j.renene.2011.07.044. 